Article

\title{
Coupling Numerical and Physical Modeling for Analysis of Flow in a Diversion Structure with Coanda-effect Screens
}

\section{Seyed Mahmood Hosseini ${ }^{1}$ * and Julie Coonrod ${ }^{2}$}

1 Civil Engineering Department, Ferdowsi University of Mashhad, P.O. Box 91775-1111, Azadi Square, Mashhad, Iran

2 Department of Civil Engineering, University of New Mexico, Albuquerque, NM 87131, USA; E-Mail: Jcoonrod@unm.edu

* Author to whom correspondence should be addressed; E-Mail: Shossein@ Ferdowsi.um.ac.ir; Tel.: +98-511-8763303; Fax: +98-511-8763301.

Received: 27 April 2011; in revised form: 23 June 2011 / Accepted: 25 June 2011 / Published: 4 July 2011

\begin{abstract}
There is an increasing need to screen water in surface water collection systems to remove floating debris and small aquatic organisms to protect receiving water bodies. Recently, the Albuquerque Metropolitan Arroyo Flood Control Authority (AMAFCA, New Mexico, USA) has actively introduced structural debris removal from storm-water facilities as a best management practice. In the South Diversion Channel Project, AMAFCA's objective is to divert the flow at the upstream end of the existing concrete structure and remove debris from this flow using Coanda-effect screens before allowing it to re-enter the channel. Design limitations, such as access to the debris removal site, existing components of the concrete structure, topography of the site, and need for flow-regulating structures complicate the design. This paper shows how numerical modeling tools (Delft3D-FLOW model) and physical modeling can be used in conjunction to observe flow patterns in a diversion structure and around Coanda-effect screens, estimate design parameters and thereby provide design recommendations.
\end{abstract}

Keywords: AMAFCA; best management practice; Coanada-effect screen; Delft3D-FLOW; diversion structure; storm water 


\section{Introduction}

Urban storm-water runoff is considered to be a major source of a wide variety of pollutants in water bodies. Therefore, there is a need to remove debris and treat such waters, if necessary. This can result in the need to divert flows in the case of existing operational channels. Recently, the Albuquerque Metropolitan Arroyo Flood Control Authority (AMAFCA, New Mexico, USA) has actively introduced structural debris removal from storm-water facilities as a best management practice. One structure which is currently under use and design is Coanda-effect screen (C-S for brevity). A C-S is a specific type of wedge-wire screen panel in which each individual wire is tilted a few degrees downstream during manufacture to produce shearing offsets into the flow above the screen. C-Ss have found many applications in agriculture, water resources management, hydropower and industry where physical and environmental considerations require liquid-solids separation and/or fish protection. They can specifically be used in rainwater harvesting filter systems, storm-water facilities and agricultural diversion systems and also as hydropower and pump intake screens.

Different features of a C-S and illustrations of the structure, related to the present study, can be found in the work of Wahl [1,2]. Figure 1, which is a modified form of Figure 1 in [2], presents side view of a typical C-S with some key elements of it. The screen is typically installed on the downstream face of an overflow weir. First, flow passes over a solid acceleration plate and then enters a wedge-wire screen panel. Wires are horizontal and perpendicular to the flow across the screen. The main objective of the acceleration plate is to deliver a smooth uniform flow that is tangential to the screen surface at the upstream edge. It can be a simple circular arc or follow the shape of the crest of an ogee spillway. Typically, the screen panel is a concave arc with a radius of curvature of approximately $3 \mathrm{~m}$, although planar screen panels can also be used [1]. The flow passing through the screen (screened flow) is collected in a conveyance channel beneath the screen, while overflow and debris pass off the downstream end of the screen. Flow velocities across the screen are typically $2-3 \mathrm{~m} / \mathrm{s}$; they increase toward the toe of the screen, and Froude numbers across the screen surface can vary from approximately 2 to 30 or greater [1]. C-Ss utilize a unique tilted-wire screen panel, where each wire is tilted a few degrees downstream to produce shearing offsets into the flow above the screen. More detailed information about the C-Ss, typical commercial details and size can be found in [1,2]. Wahl [2] provided a detailed description of the applications, design parameters, design procedure, and design recommendations for this screen. Wahl [1] developed a theoretically based model and a computer program for the hydraulic performance of C-Ss. This model predicts the discharge through the screen and overflow off the screen, which are the variables of interest in many applications.

From a practical point of view, C-S is a self-cleaning screen with no moving parts; it offers the potential for economically screening fine materials with minimal clogging and cleaning maintenance. It has been used for debris removal and fish exclusion at several prototype sites. Figure 2 depicts an example of such a structure, which is under operation at one of the surface water collection channels in Albuquerque. Figure $2 \mathrm{a}$ shows the upstream channel and left side of the screen, whereas Figure $2 \mathrm{~b}$ depicts the right side of the screen. Also shown in Figure $2 b$ are holes connected to upwardly inclined pipes that act as emergency bypass. Figure $2 \mathrm{c}$ shows the view from underneath the screen. The semicircular flume on the top conveys some small portion of the screened water to a small nearby detention pond (not shown in the figure), which is used to recharge the ground water. The main portion 
of the screened water flows to the circular diversion tunnel depicted in Figure $2 \mathrm{~d}$. The main features of this structure are its design setup and components, which can be unique to any specific location. In other words, these features are site-specific; to the best of the authors' knowledge, no design recommendations or guidelines, apart from the available classical hydraulic equations, can be found in design standards and textbooks. Therefore, this study focused on some design aspects related to the diversion structure and C-S setup for the South diversion channel (SDC) in Albuquerque.

The paper is organized as follows: The next section provides the materials and methods of the study. It describes the project and introduces physical and numerical method setup procedure. Then, the results are presented and discussed. Finally, general conclusions are drawn from this study.

Figure 1. Side view of a typical Coanda-effect screen.

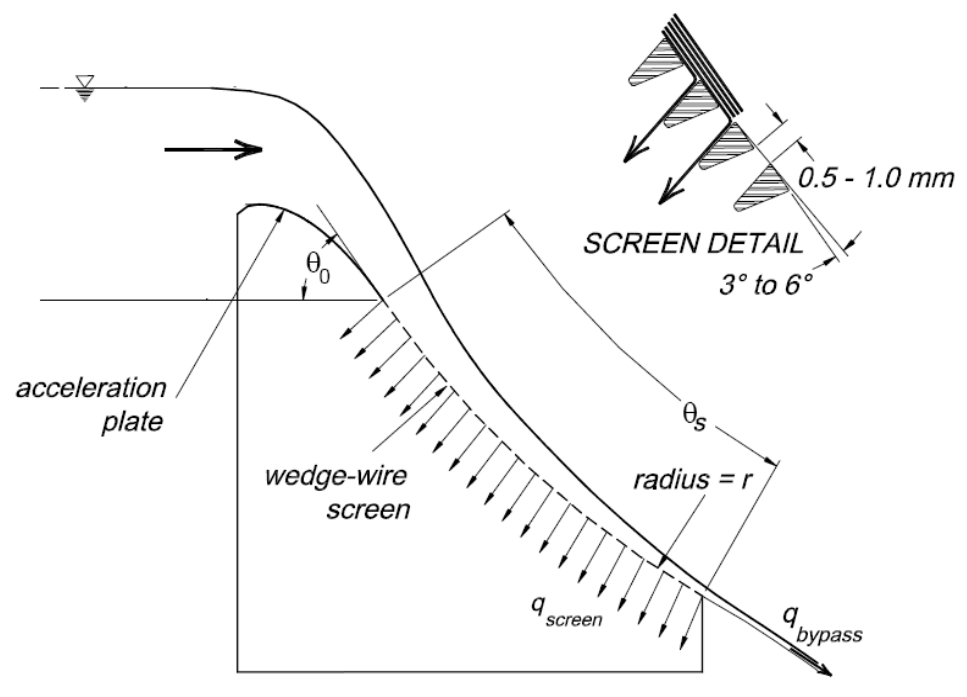

Figure 2. Different components of a debris removal structure with Coanda-effect screen.

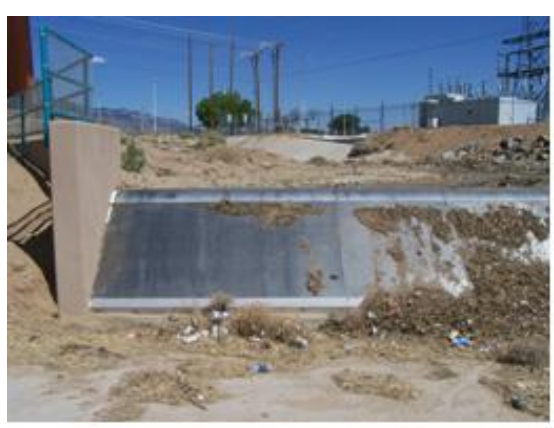

(a)

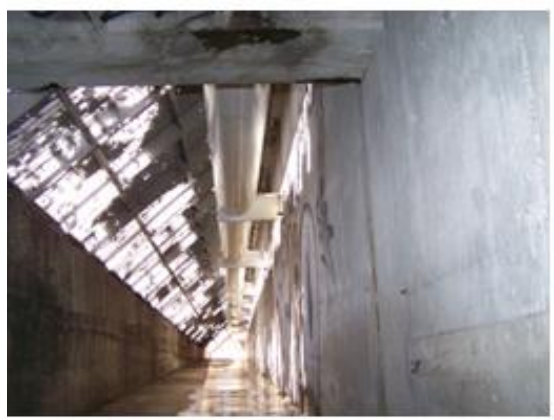

(c)

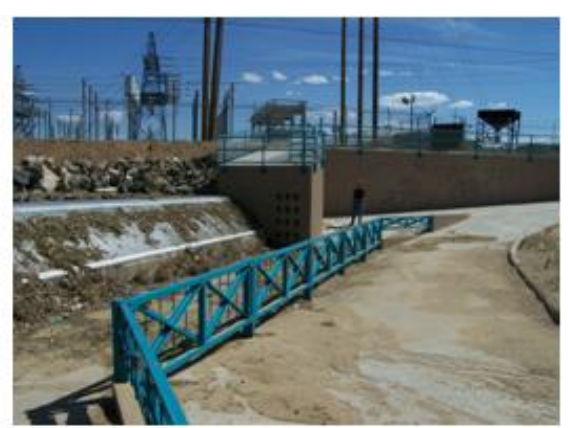

(b)

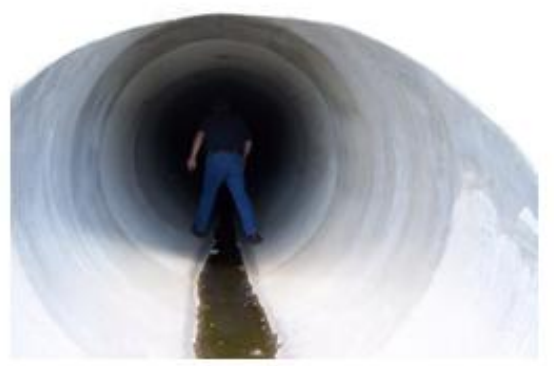

(d) 


\section{Materials and Methods}

\subsection{Site Description and Design Characteristics}

SDC is one of the main storm-water collectors in Albuquerque. The upstream portion of AMAFCA's SDC collects storm-water runoff from the area east of Interstate 25 and south of the University of New Mexico area. SDC receives storm water from storm-water drains, the Genievas Arroyo, and the Kirtland Arroyo before crossing Interstate 25. A concrete baffle chute is located on the channel approximately $240 \mathrm{~m}$ downstream of its Interstate 25 crossing (Figure 3).

Figure 3. Image map of the project site.

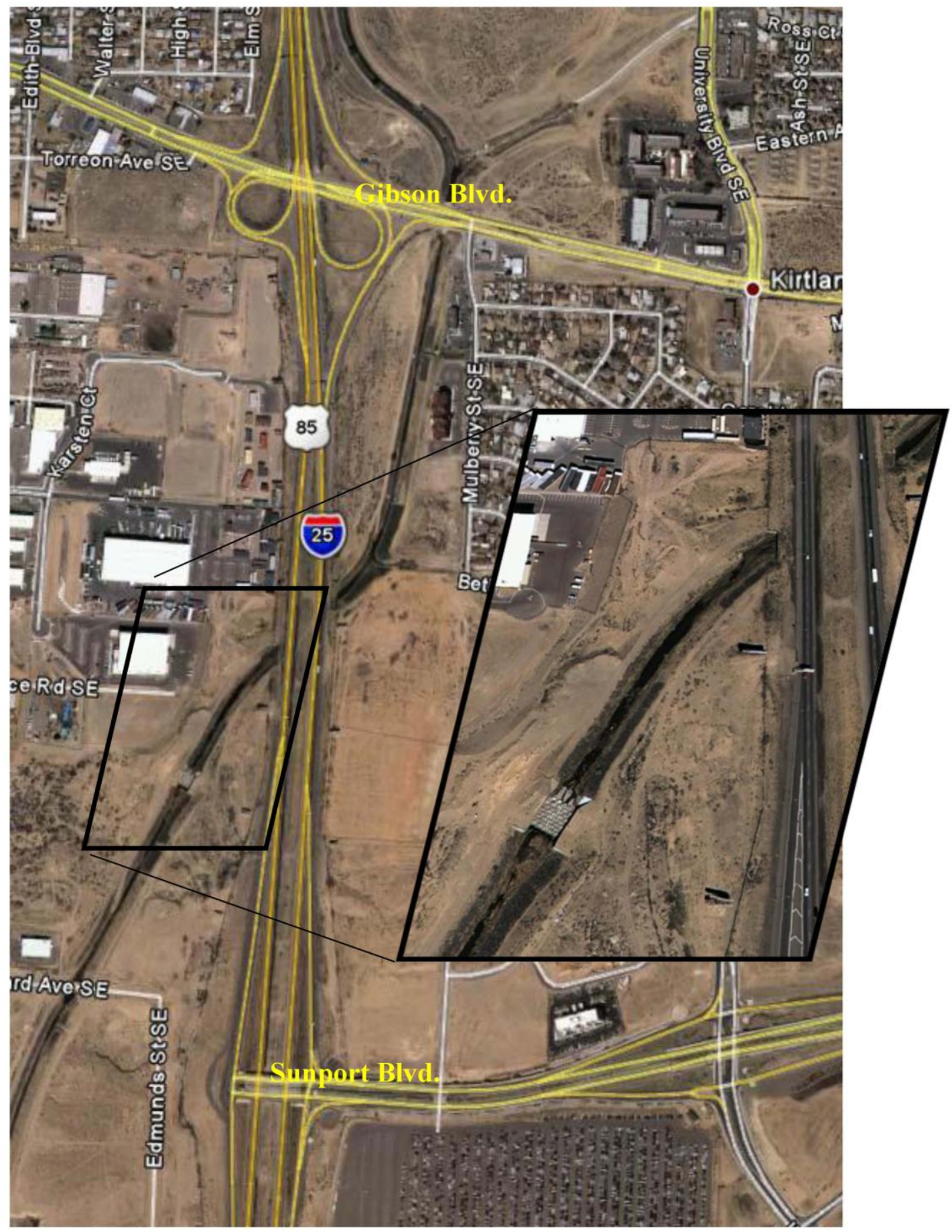


SDC is a trapezoidal channel with an earthen bottom width of $9.0 \mathrm{~m}$ and riprap side slopes with a vertical $(V)$ /horizontal $(H)$ ratio of $1: 2$. The channel has a longitudinal slope of $0.14 \%$ just upstream of the baffle chute. The Manning roughness coefficient of the channel is estimated to be 0.035 . Although the channel has been designed for a discharge of $97.70 \mathrm{~m}^{3} / \mathrm{s}$, the more frequent discharges in the channel vary between 3 and $16 \mathrm{~m}^{3} / \mathrm{s}$. All the reported data were obtained from initial design reports which are available in the AMAFCA office. Figure 4 shows different views of the channel and baffle chute. They depict the existing condition of the channel. Figure 4 a shows a general view of the baffle chute while the SDC is also observed at downstream and upstream of the baffle chute. Figure $4 \mathrm{~b}$ refers to the downstream condition of the baffle chute and existing condition of the SDC.

Figure 4. Photos depicting the existing condition of the SDC and baffle chute, (a)-general view and (b)-downstream condition.

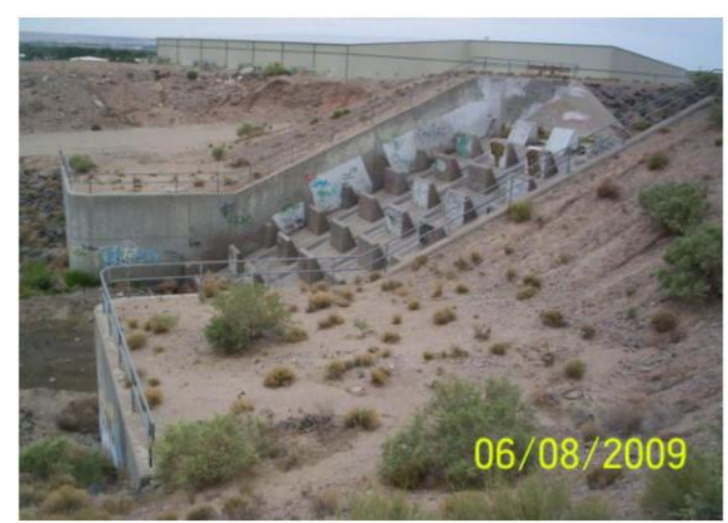

(a)

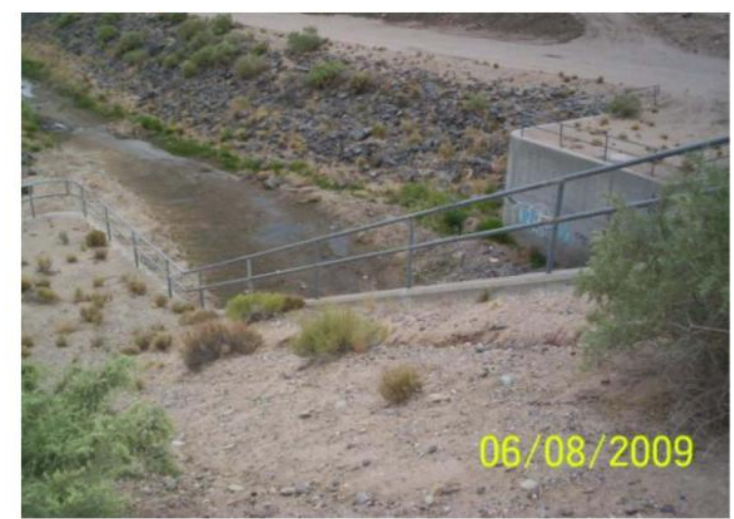

(b)

AMAFCA's objective is to divert flow at the upstream end of the existing concrete structure and remove debris from this flow before allowing it to re-enter the SDC. Figure 5 depicts the general layout for one the design alternatives considered in this project. The cross-hatched area shows the designed location for screens to remove floating debris under the designed flow rates. The inflow discharge and the depth and velocity behind the screens and the Froude number are the main variables that determine the required length and width of the screens - the two parameters that directly affect the cost of the screen setup. The proposed geometry for the diversion structure including the screen setup is based on scientific and technical reasons. In this design, the settlement of suspended sediments, easy access to the sediment deposition zone and screens, economy of the design, and hydraulic performance of the system had been considered. These factors are necessary for providing a suitable ground to remove the trapped floating debris and sediments from the site, reduce the cost, and create a uniform distribution of flow around the screens. Among these, the final item can also help in determining variables necessary to design the screen dimensions, which can lead to an optimum and cost-effective design of the screen. In the initial design, the two $10.50 \mathrm{~m}$ walls ( $H I$ and $P Q$ ) are the existing wing walls that remain fixed. Except for the $1.80 \mathrm{~m}$ drop structure at the beginning, sill and ogee spillway, the bottoms of all other parts of the diversion structure up to the screens are at the same level. The following paragraphs describe different design components.

Starting from upstream, while the main direction of existing flow is to the baffle chute, flow is blocked and diverted to the left and right directions towards the screens. The idea is to divert the first 
$15.49 \mathrm{~m}^{3} / \mathrm{s}$ to the left direction and the next $15.49 \mathrm{~m}^{3} / \mathrm{s}$ up to $30.98 \mathrm{~m}^{3} / \mathrm{s}$ to the right direction. Flows higher than $30.98 \mathrm{~m}^{3} / \mathrm{s}$ must flow to the baffle chute in the original direction of flow. A $1.8 \mathrm{~m}$ high and $9.0 \mathrm{~m}$ wide drop structure has been considered at the confluence of the channel with the diversion structure. In addition to its role in local energy dissipation, the main advantage of this drop structure is that it reduces any backwater effect resulting from the placement of this diversion structure. A broad-crested weir (sill) with a height of $0.6 \mathrm{~m}$ and top width of $1.8 \mathrm{~m}$ was considered for the left direction. Another structure that was considered is an ogee spillway on the right side. This spillway prevents the first $15.49 \mathrm{~m}^{3} / \mathrm{s}$ flow from going to the right direction, and its height and width must be adjusted by taking this into consideration. Both the left and the right sides must have the capacity to convey a total discharge of $30.98 \mathrm{~m}^{3} / \mathrm{s}$. Discharges higher than $30.98 \mathrm{~m}^{3} / \mathrm{s}$ up to $97.7 \mathrm{~m}^{3} / \mathrm{s}$ must flow in the main direction of the flow towards the baffle chute. This requires that a weir or a spillway be used along the $K L N$ section. Although the end points of the $K L N$ section are connected to the sill and ogee spillway and the width of this section is fixed depending on the location of the ogee spillway on the right, the height along KLN must be adjusted to function properly. Two sluice gates were considered for the sill and ogee spillway. These two gates add flexibility to the design. The first sluice gate, which is related to the sill, allows the operator to adjust the flow to nearly $15.49 \mathrm{~m}^{3} / \mathrm{s}$ to the left at higher discharges; the second sluice gate, which is related to the ogee spillway, functions similarly to adjust flows of nearly $15.49 \mathrm{~m}^{3} / \mathrm{s}$ to the right side. Flow rates higher than $97.7 \mathrm{~m}^{3} / \mathrm{s}$ and even $15.49 \mathrm{~m}^{3} / \mathrm{s}$ are less frequent and not very important in terms of debris removal. The zone behind the sill and spillways can act as a settling basin to settle the suspended sediments.

Figure 5. Layout and main dimensions of the design in meters.

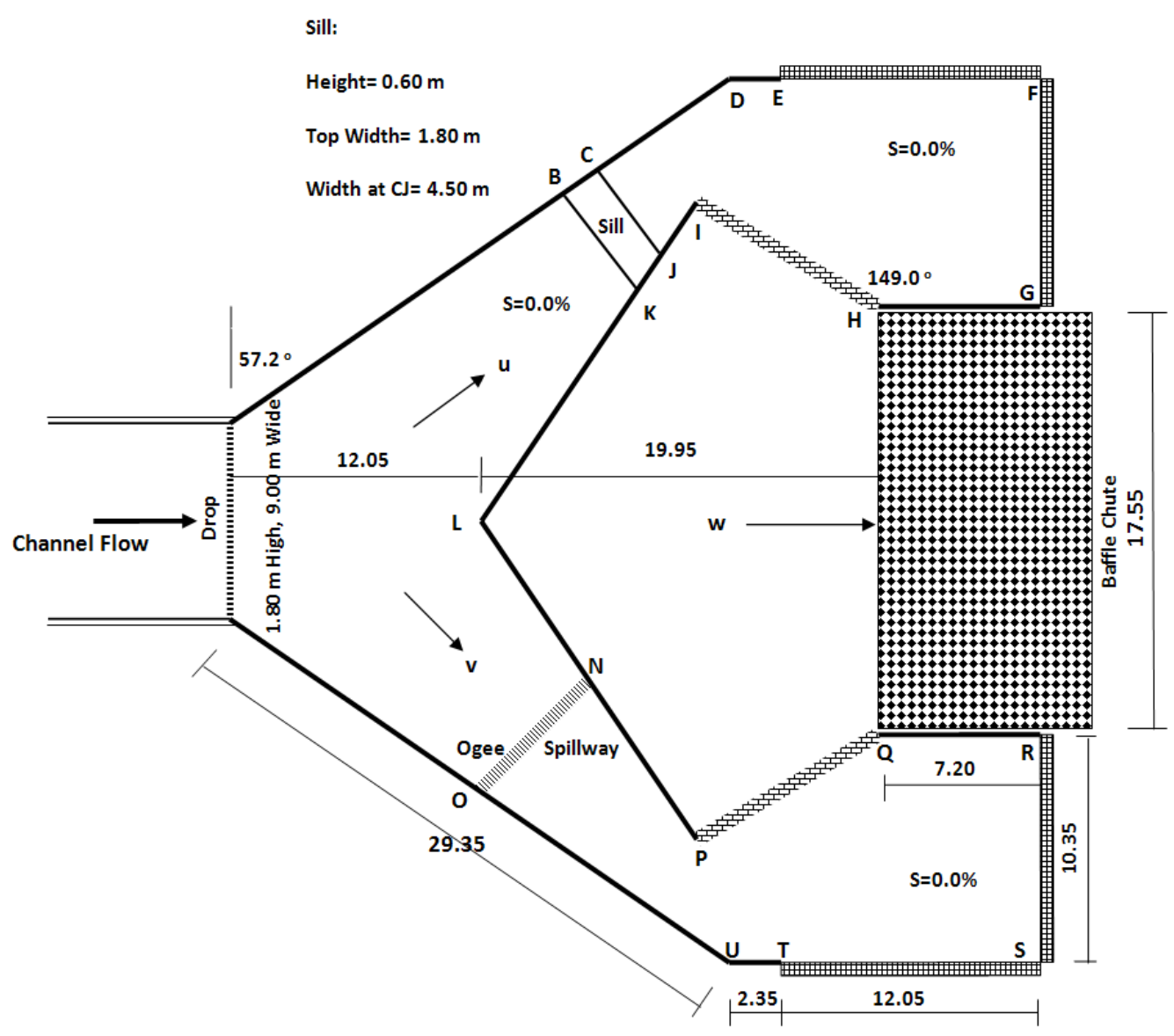


The complicated nature of the flow is evident in this design. Many factors such as the geometry and topography contribute to this complexity, which makes it necessary to use appropriate analysis tools such as physical and numerical modeling in addition to classical design methods.

Although the mechanisms used to divert flow are briefly discussed, this study focused on flow observation and detailing in the zone behind the C-S. The Delft3D-FLOW numerical model, which is a commercially available software program, and physical modeling were used to achieve this. Although the existence of floating debris and sediments can affect water properties and flow behaviour, such secondary effects were ignored for urban water system considered in this study. Therefore, both physical and numerical models were developed for clear water condition.

\subsection{Physical Model Setup}

With reference to the explained design features depicted in Figure 5, two main specific objectives were considered for the physical model:

(1) To observe flow patterns for different specified flow rates around C-Ss and provide some depth measurements at specific locations to estimate physical parameters for the simple CFD model used in this study. Although numerical modeling can produce detailed information about the flow pattern, velocity, and depth around a $\mathrm{C}-\mathrm{S}$, there are aspects of the flow that need further clarification, and observation in the physical model was quite useful in this regard.

(2) To observe flow patterns at the point of diversion and extract necessary data for designing the height and width of the ogee spillways along the $O N$ and $K L N$ sections. Although such designs can be made by using available classical methods, the use of such an inexpensive physical model can further validate standard designs, especially for the shaped ogee spillway along KLN with the proposed geometry.

The existing trapezoidal channel at the Civil Engineering Department Hydraulics Laboratory, University of New Mexico was used to build the physical model. Figure 6 shows a general configuration of the sheet metal channel with a bottom width of $0.3 \mathrm{~m}$ and side slopes of $2: 1(\mathrm{H}: \mathrm{V})$. The longitudinal slope can be adjusted. A $1 / 30$ scale allowed for use of the existing channel $(0.3 \mathrm{~m}$ bottom width of the modeled channel $=9.0 \mathrm{~m}$ bottom width of the prototype channel) and was appropriate for the pump capacity to produce the different discharges necessary in the study. All discharges developed at this scale were also measurable volumetrically using 18- and 4-gallon containers and a stop watch. The maximum relative error in discharge measurement was estimated to be $5 \%$ and $2.5 \%$ for high and low discharges considered in this study. Considering the existence of a $0.06 \mathrm{~m}$ drop in the beginning of the modeled diversion structure, we decided to build the model off the flume table right at the end of the flume. The legs of the modeling table were adjustable using screws, which made it possible to have a flat bottom at the desired elevation. The Froude number similitude for open-channel, free-surface flows was used to determine the similitude relationships between the model and the prototype variables and to convert modeling values to the corresponding prototype values. Physical modeling activities were organized in two steps to achieve the two main objectives of the study. 
Figure 6. Picture showing the general configuration of the flume and physical model.

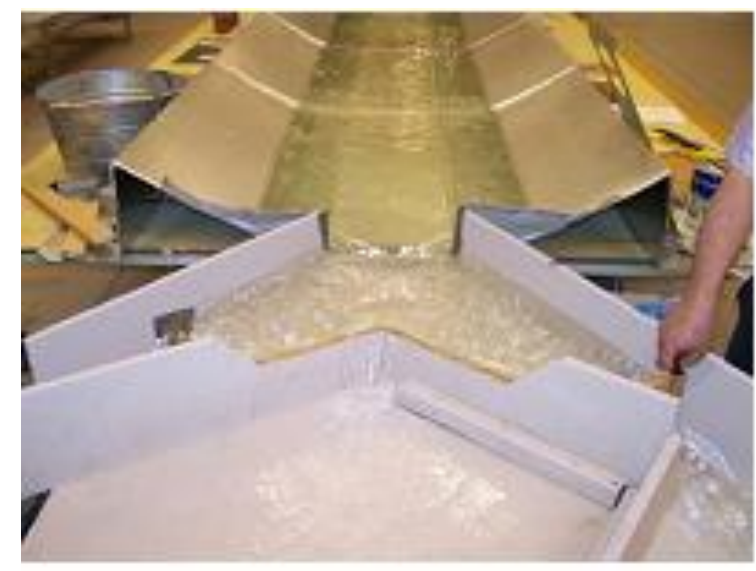

In the first step, half of the model was built. Figure 7 shows a sketch of this setup whose major dimensions were determined from Figure 5 on the basis of the 1/30 scale of the model. It is worth mentioning that the slope of the flume did not have an important role in this study because the flow pattern after the drop and, more specifically, after, the sill was the centre of focus, and the flow was governed either by the critical condition at the drop or depth at the sill. Both the model and prototype were turbulent. The physical modeling activity was to run different flows $(0.686 \mathrm{~L} / \mathrm{s}$ corresponding to $3.38 \mathrm{~m}^{3} / \mathrm{s}$ in prototype) and high discharges (3.142 L/s corresponding to $15.49 \mathrm{~m}^{3} / \mathrm{s}$ in prototype) through the system, observe the flow pattern at different zones of interest, and measure depth at some key locations. The effect of using a smooth curved wall at point $D$ was also studied in this case. Since the same scenarios were also produced in the numerical model, further details about the scenarios are given in the numerical modeling section (Section 2.3) and results and discussion (Section 3).

Figure 7. Extent and dimensions of the physical model.

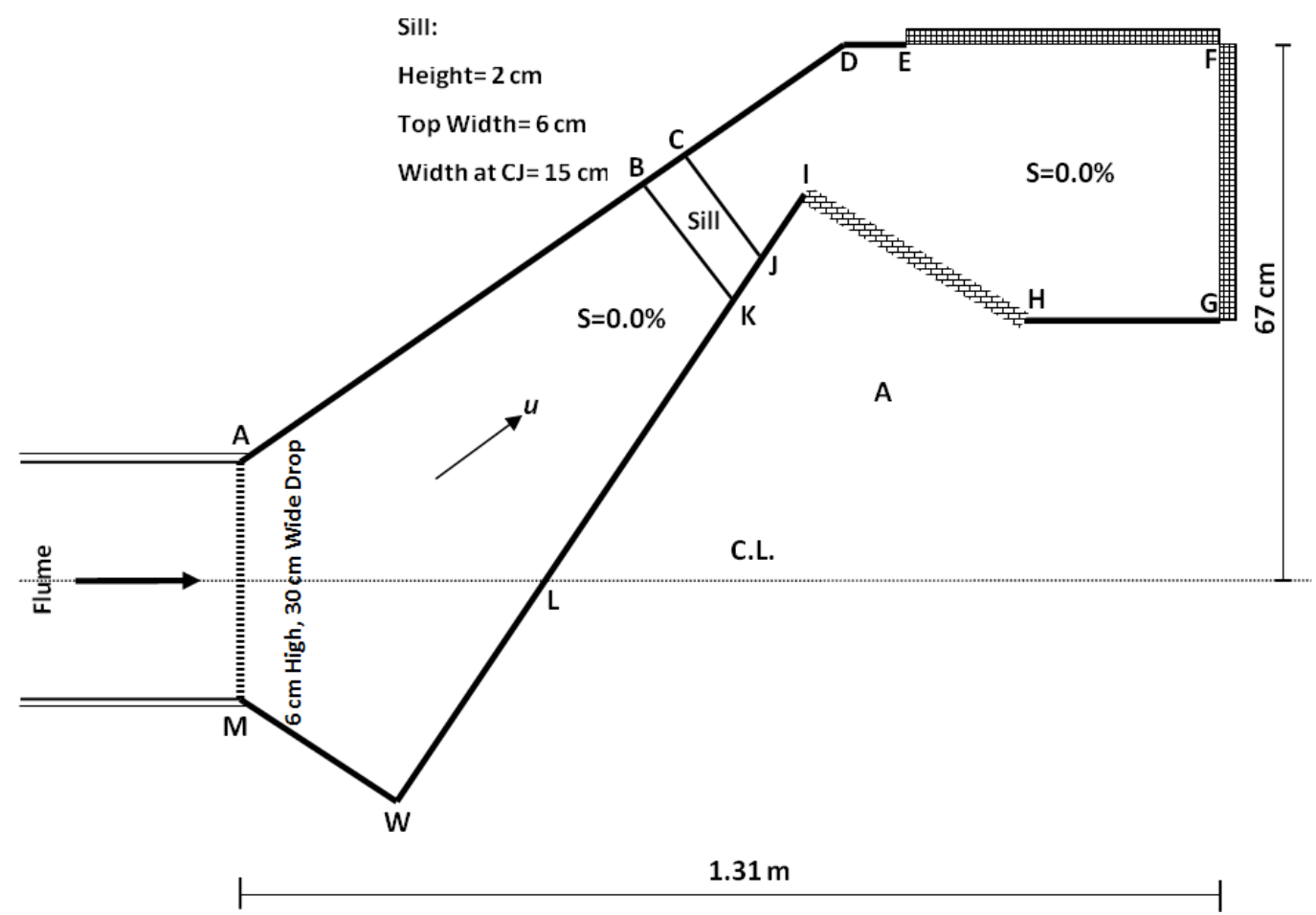


In the second step, the physical model was built to be almost complete; it included the $v$ and $w$ directions of flow, as shown in Figure 5. This setup was used to adjust the height of different spillways along sections $N O$ and $K L N$. The main objective of this paper is to study the flow behind and around the C-Ss or after the sill, as shown in Figure 7, using the first step of physical and numerical modeling. Therefore, the procedure for adjusting the spillway heights is briefly introduced here, and major dimensions are given.

The width of section NO for building ogee weir was considered to be $0.25 \mathrm{~m}$. This selection was based on the balance between providing an appropriate zone for sediment deposition and increasing the width of the spillway to reduce any backwater effect. To adjust the height of the weir along $N O$, a discharge of $3.142 \mathrm{~L} / \mathrm{s}$ (corresponding to $15.49 \mathrm{~m}^{3} / \mathrm{s}$ in the prototype) was run through the system; with no flow in the $v$ and $w$ directions, the height of the ogee spillway was found to be $0.08 \mathrm{~m}$. An ogee-shaped spillway was considered along section $K L N$. The triangular shape increased the effective length of the spillway and thus reduced the backwater effect on the flow in the channel. It also helped in dissipating energy downstream of the spillway when the flow jets hit each other. The lengths of section $K L N$ are 0.45 and $0.30 \mathrm{~m}$ in the $K L$ and $L N$ parts, respectively; they have a total length of $0.75 \mathrm{~m}$. To adjust the heights along $K L N$, a discharge of $6.284 \mathrm{~L} / \mathrm{s}$ was run through the system. A gate was installed at the sill. The opening of the gate was controlled to let nearly $3.142 \mathrm{~L} / \mathrm{s}$ run in the $u$ direction and another $3.142 \mathrm{~L} / \mathrm{s}$ run in the $v$ direction towards the weir along the $N O$ section. Observations and measurements made behind the weirs showed that the required heights at points $K, L$, and $N$ were $0.115,0.121$ and $0.117 \mathrm{~m}$, respectively. These numbers indicate a sloped condition along $K L N$. Observations showed that this condition provided a more uniform distribution of flow along the section. All the physical model length, width, and height numbers can be converted to prototype values if multiplied by 30. Although no manual operation is required for discharges less than $15.49 \mathrm{~m}^{3} / \mathrm{s}$, this design also indicates a need for a gate at the sill to adjust the flow rate in both directions for discharges between 15.49 and $30.98 \mathrm{~m}^{3} / \mathrm{s}$. Obviously, for less frequent discharges of more than $30.98 \mathrm{~m}^{3} / \mathrm{s}$ when the $K L N$ spillway is also operating, a control gate is required above the $N O$ spillway for adjusting the flow rate in different directions. In general, while these two control gates add flexibility to the design, there is a need to manually operate them in the field under high but less frequent discharges. The gate openings were also adjusted.

\subsection{Numerical Model Setup}

Commercial CFD software is widely used in engineering design. It has the advantage of comprehensive validation against many hypothetical and laboratory test cases, a graphical user interface, and a large number of different models for physical phenomena, such as the representation of turbulence. In hydraulics and river engineering works, CFD can be used in different ways including as a method for improving conveyance estimation to enhance one-dimensional and two-dimensional models, as a technique for assessing the performance of small-scale river engineering works and hydraulic structures such as river intakes/outtakes, weirs, fish passes and sluice gates, and as a scientific tool for developing understanding of the fundamental fluid dynamics of flow in rivers [3]. 
Considering that most CFD codes have been developed for mechanical engineering works, the application of CFD to hydraulic problems raises a number of issues related to geometry, free surface, boundary conditions, hydraulic roughness, flow regime and turbulence [3].

Delft3D-FLOW is a commercial software program available from WL|Delft Hydraulics (now Deltares) and was used in this study. Delft3D-FLOW is the hydrodynamic module of Delft3D, which is WL|Delft Hydraulics' fully integrated program for modeling water flows, waves, water quality, particle tracking, ecology, sediment and chemical transport, and morphology. Its capability for modeling subcritical-supercritical free surface flows, handling different types of boundary conditions, and availability of different turbulence models made the model suitable for use in this study. Mesh generation capabilities and bathymetry or topography generation are other powerful features available in this software. In addition, a trial version of the model with some technical support from the model provider made the model a good candidate for use in this study.

The following is a brief description of the model related to this study, as drawn from the user manual for Delft3D-FLOW [4]. Delft3D-FLOW is a multi-dimensional (2D or 3D) hydraulic (and transport) simulation model; it essentially solves the Navier-Stokes equations for incompressible fluid under shallow water and Boussinesq assumptions. In the vertical momentum equation, the vertical acceleration is neglected, which leads to the hydrostatic pressure distribution. In 3D models, the vertical velocities are computed from the continuity equation. The set of partial differential equations in combination with an appropriate set of initial and boundary conditions is solved on a finite difference staggered grid. In the horizontal direction, Delft3D-FLOW uses structured orthogonal curvilinear coordinates. Both Cartesian and spherical coordinates are supported. In the vertical direction, Delf3D-FLOW offers two different vertical grid system, the $\sigma$ coordinate system ( $\sigma$-grid) and the Cartesian coordinate system (Z-grid). In the $\sigma$-grid, the vertical grid consists of layers bounded by two sigma planes; these are not strictly horizontal but follow the bottom topography and free surface. Because the $\sigma$-grid is boundary-fitted both to the bottom and to the moving free surface, a smooth representation of the topography is obtained. In order to capture non-hydrostatic flow phenomena in special cases, the hydrostatic version of the Cartesian grid (Z-model), which is part of the Delft3D modeling suite, has been extended with a non-hydrostatic module.

In this study, the idea was to keep the structure of the model as simple as possible without a serious need to calibrate parameters. Meanwhile, observations in the physical model showed that the flow has a high width to depth ratio especially around the C-Ss. Therefore, the $2 \mathrm{D}$ depth-averaged model of Delf3D-FLOW in a one-layer $\sigma$-grid system was used to model the flow system shown in Figures 5 and 7. This model can provide a reasonable distribution of depth and velocity field required in this study. The numerical model was developed for the full or prototype scale of the flow system for the geometry shown in Figure 7. Developing the model for the prototype scale made the modeling results directly available for use in design and analysis.

Similar to any conventional numerical model development, the following steps, which correspond to the Delft3D-FLOW graphical user interface menu and module setup, were followed.

(1) First, the extent of the area to be modeled was selected; this includes the definition of the location and extent of open boundaries and the land-water boundary. Although Figure 7 presents the domain of the problem at hand, two boundaries E2-F2 and F2-G2, which are shown in Figure 8, were artificially defined to model the free overfall over the boundaries $E F$ and $F G$. In other words, the 
bathymetry and water levels at boundaries $E 2-F 2$ and $F 2-G 2$ were defined so low that a free overfall could occur at boundaries $E F$ and $F G$. Figure 8 also shows the monitoring/observation points whose information were extracted and used in analysis.

Figure 8. Modeled area and monitoring/observation points.

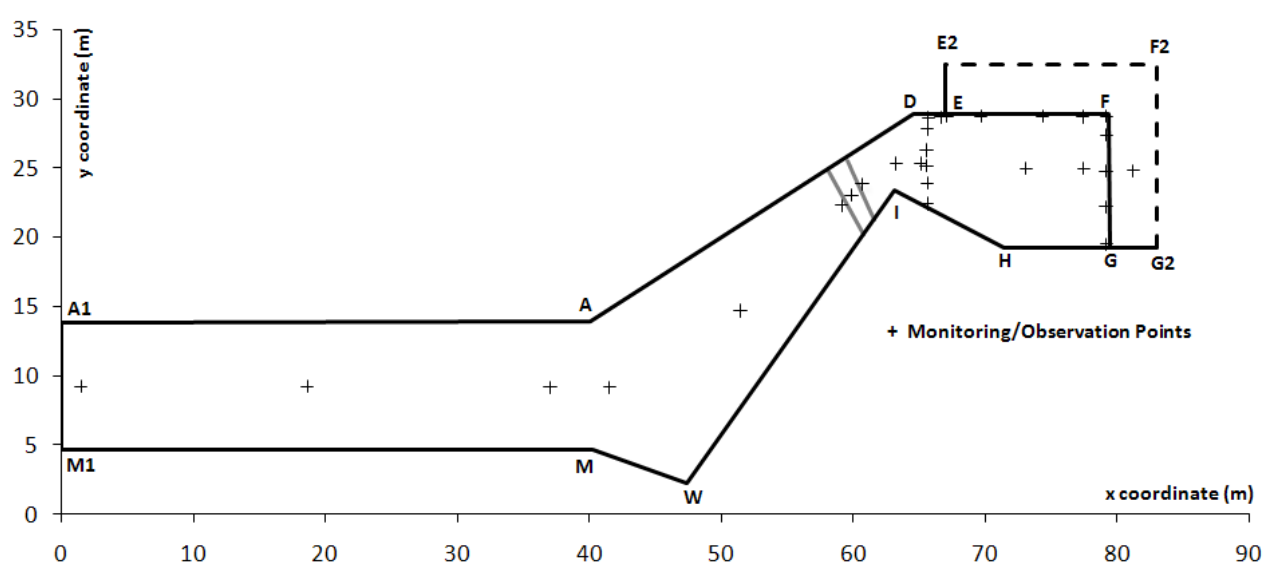

(2) The numerical grid shown in Figure 9 was generated, and bathymetry was defined on the numerical grid. These were done using modules available in the software. The generated grid is the result of a trial-and-error procedure for selecting optimum parameters for grid size and distribution. In doing so, by covering the geometry and well-defined angles in the horizontal plane, higher resolutions near the zones of interest for flow analysis and in areas with sudden changes in bed topography (e.g., drop locations) were considered. The bathymetry was developed from a set of given sampled data from the bed elevation using interpolation techniques available in the bathymetry module of the software. Sharp changes in the bed elevation at locations such as drops were accurately captured in the generated bathymetry. This was achieved by using visualization capabilities in the modules that help in detecting any anomaly in geometry and bathymetry. In brief, with respect to a horizontal plane of reference, the bed elevations in the inflow section ( $A 1-M 1$ in Figure 8), just upstream the drop $A M$, just downstream the drop $A M$, above the sill, right at the crest of the drops $E F$ and $F G$ and at artificially defined boundaries E2-F2 and $F 2-G 2$ are 12.03, 11.99, 10.19, 10.79, 10.19 and $6.00 \mathrm{~m}$, respectively. This information is helpful in interpreting water level data.

Figure 9. Grid used for numerical analysis.

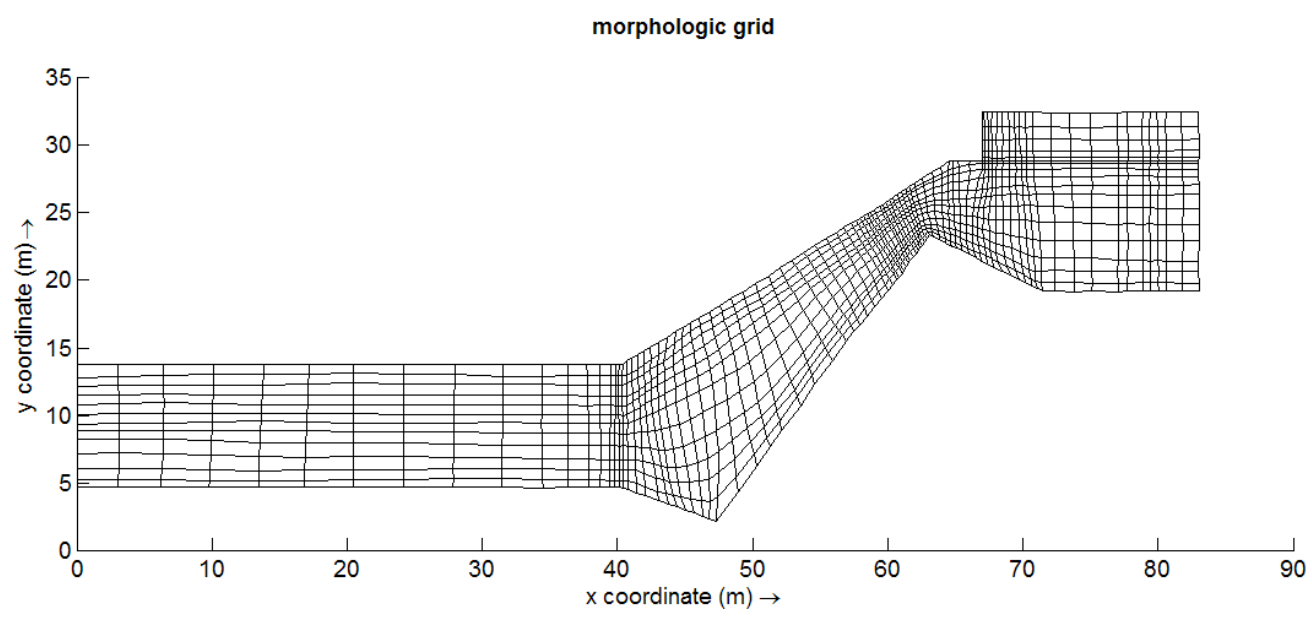


(3) Different flow scenarios corresponding to the objectives of the study and physical model measurements were considered. Table 1 presents these scenarios with some basic descriptions. It should be considered that the selected downstream water levels along E2-F2 and F2-G2 boundaries, which correspond to small depth values of $0.2 \mathrm{~m}$ and $0.1 \mathrm{~m}$, for high and low discharges, respectively, do not affect the results in the areas of interest.

Table 1. Different flow scenarios.

\begin{tabular}{|l|l|l|l|l|l|l|}
\hline \multirow{2}{*}{ Description/design variable } & \multicolumn{3}{|c|}{ High discharge } & \multicolumn{3}{c|}{ Low discharge } \\
\cline { 2 - 8 } & Sharp & Curved & Curved with vane & Sharp & Curved & Curved with vane \\
\hline Acronym & HDS $^{\text {a }}$ & HDC & HDCV & LDS & LDC & LDCV \\
\hline Discharge $\left(\mathrm{m}^{3} / \mathrm{s}\right)$ & 15.49 & 15.49 & 15.49 & 3.38 & 3.38 & 3.38 \\
\hline $\begin{array}{l}\text { Downstream water level along } \\
E 2-F 2 \text { and } F 2-G 2 \text { boundaries }(\mathrm{m})\end{array}$ & 6.2 & 6.2 & 6.2 & 6.1 & 6.1 & 6.1 \\
\hline
\end{tabular}

${ }^{a}$ HDS, HDC, and HDCV refer to high discharges with an angled sharp corner, smooth corner, and smooth corner with a non-submerged vane in the middle of the wall, respectively, along wall $C D E$. Other scenarios are similarly named for low discharges.

(4) Initial and boundary conditions in agreement with the physics of the flow and numerical accuracy and simplicity were defined. A uniform value of water level was considered for the initial condition. This value was $12.35 \mathrm{~m}$ for low discharges (LDS, LDC and LDCV scenarios) and $12.90 \mathrm{~m}$ for high discharges (HDS, HDC and HDCV scenarios). The selection of these values corresponds to the selection of upstream boundary conditions, which is described below. Thirty three minutes was found to be much more than the time required to reach the final steady-state condition. This was studied by looking at the variations of the outputs with time at different locations. Figures showing the variations of instantaneous discharges with time, presented in Section 3, support the approach. Therefore, the following time frame was set for the model to run. Reference date: 12 June 2009; simulation start time: $00 \mathrm{hr}$ 00min 00sec, simulation stop time: 00hr 33min 00sec; time step: 0.0001375 day. The selected time step produces stable and accurate results in interaction with the grid size and other numerical and physical parameters, which are introduced in the next items. Among the different types of the boundary conditions supported by Delft3D-FLOW are total discharge boundary condition, discharge per grid cell and water level boundary conditions. In the first step, a total discharge boundary condition was selected for the upstream inflow boundary, and a water level boundary condition was applied at the outflow boundaries along the E2-F2 and F2-G2 sections. Unfortunately, in the results, oscillation at the final steady-state depth and discharge values was present. Different measures, such as adjusting the numerical and physical parameters and changing the location of upstream inflow boundaries, were employed to reduce the amplitude of the oscillations. Although moving the location of the upstream inflow section further upstream reduced the amplitude of oscillations at downstream observation points and sections, the oscillations were not completely eliminated. In communications with the model developer, it was explained that the total discharge boundary condition uses the computed water depth just downstream of the boundary to distribute the discharge. Although the model developer explained that this procedure cannot work well in the case of supercritical flows due to the physics of flow, our experience shows that in general, the interaction between depth and discharge adjustment used in the procedure, can result in oscillations that decrease 
as flow moves downstream. A discharge per cell boundary condition, i.e., dividing the upstream discharge by the total number of cells, was not used in this study due to the different sizes of the cells. A very effective type of upstream boundary condition was the constant water level boundary condition. This constant depth, with some accepted tolerance (less than $2 \%$ of the estimated normal depth of the channel), for low and high discharges was selected based on three sets of data or information: (1) create a depth close to but less than the estimated normal depth in the upstream channel; (2) create a depth close to the depth obtained by taking the moving average of the upstream depths produced by applying the previously described total discharge boundary condition; and (3) create total discharges in agreement with the total discharges reported in Table 1 for each scenario when adjusting or calibrating horizontal background eddy viscosity, as described later. Considering that the flow after the sill and around and behind the C-Ss was the main focus of this study, no tolerance was accepted for discharge, and continuity was satisfied in all sections including the upstream inflow section. A free overfall condition was observed for the first drop in the numerical results, which agrees with the physical model observations.

Therefore, time series forcing type boundary conditions with the following values were applied to reach the desired final steady-state condition.

For high discharge scenarios:

\begin{tabular}{|c|c|c|}
\hline Time & Upstream Water Level & $\begin{array}{l}\text { Downstream Water Level Along } \\
\text { Sections } \boldsymbol{E 2 - F 2} \text { and } \text { F2-G2 }\end{array}$ \\
\hline 000000 & $12.90 \mathrm{~m}$ & $12.90 \mathrm{~m}$ \\
\hline 002200 & $12.90 \mathrm{~m}$ & $6.20 \mathrm{~m}$ \\
\hline 003300 & $12.90 \mathrm{~m}$ & $6.20 \mathrm{~m}$ \\
\hline
\end{tabular}

For low discharge scenarios:

\begin{tabular}{|c|c|c|}
\hline Time & Upstream Water Level & $\begin{array}{l}\text { Downstream Water Level Along } \\
\text { Sections } \boldsymbol{E 2 - F 2} \text { and } \text { F2-G2 }\end{array}$ \\
\hline 000000 & $12.35 \mathrm{~m}$ & $12.35 \mathrm{~m}$ \\
\hline 002200 & $12.35 \mathrm{~m}$ & $6.10 \mathrm{~m}$ \\
\hline 003300 & $12.35 \mathrm{~m}$ & $6.10 \mathrm{~m}$ \\
\hline
\end{tabular}

(5) The physical parameters for the 2D depth-averaged model of Delf3D-FLOW in a one-layer $\sigma$-grid system were selected as follows. A constant gravitational acceleration of $9.81 \mathrm{~m} / \mathrm{s}^{2}$ and water density of $1000 \mathrm{~kg} / \mathrm{m}^{3}$ were used. The Manning roughness formula with a constant Manning roughness coefficient of 0.013 was selected to represent the bottom roughness in the diversion structure made of concrete. A no-slip condition was applied to the walls. The process of secondary flow, which adds the influence of helical flow to the momentum transport, was ignored. In Delft3D-FFLOW, secondary flow is only displayed for depth-averaged computations using the $\sigma$-grid.

In Delft3D-FLOW, for the Reynolds-averaged Navier-Stokes equations, the Reynolds stresses are modeled using the eddy viscosity concept [5]. This concept expresses the Reynolds stress component as the product between a flow as well as grid-dependent eddy viscosity coefficient and the corresponding components of the mean rate-of-deformation tensor. The meaning and the order of the eddy viscosity coefficients differ for $2 \mathrm{D}$ and $3 \mathrm{D}$, for different horizontal and vertical turbulence length 
scales and fine or coarse grids. For 3D shallow water flow, the stress tensor is anisotropic. The horizontal eddy viscosity coefficient is much larger than the vertical eddy viscosity. The horizontal viscosity coefficient may be a superposition of three parts.

The horizontal eddy-viscosity is mostly associated with the contribution of horizontal turbulent motions and forcing that are not resolved (sub-grid scale turbulence) either by the horizontal grid or a priori removed by solving the Reynolds-averaged shallow-water equations. For the latter, Delft3D-FLOW introduces the horizontal eddy-viscosity $v_{H}^{\text {back }}$ and for the former the sub-grid scale (SGS) horizontal eddy-viscosity $v_{S G S}$. For the latter, Delft3D-FLOW simulates the larger scale horizontal turbulent motions through a methodology called Horizontal Large Eddy Simulation (HLES). The associated horizontal viscosity coefficient $v_{S G S}$ is then computed by a dedicated SGS turbulence model. The 3D part $v_{3 D}$ is referred to as the three-dimensional turbulence, and in $3 \mathrm{D}$ simulations it is computed following a 3D-turbulence closure model. The background horizontal viscosity can have user-defined uniform or space varying values. Consequently, in Delft3D-FLOW the horizontal eddy-viscosity coefficient is denoted by [4]:

$$
v_{H}=v_{S G S}+v_{3 D}+v_{H}^{b a c k}
$$

It is noted that the background horizontal eddy viscosity represents a series of complicated hydrodynamic phenomena. An overview of different eddy viscosity options in Delft3D-FLOW shows that depending on the selected option, this background horizontal eddy viscosity either contains zero, one or two contributions [4]. Within the context of the model used in this study and the objectives and availability of data, the option of a 2D-turbulence model with no HLES was used. In this case, conceptually, the background horizontal eddy viscosity contains $2 \mathrm{D}$ turbulence effects plus the dispersion coefficient. In simulations with the depth-averaged momentum equations, the redistribution of momentum due to the vertical variation of the horizontal velocity is denoted as dispersion. In this paper, a uniform background horizontal eddy viscosity was considered and manually calibrated. This procedure is described later.

(6) Numerical parameters were specified based on the physics of flow and the recommendations made in the Delft3D-FFLOW user manual. Numerical parameters are mainly related to drying and flooding and some other advanced options for numerical approximations. The Delft3D-FLOW user manual has a detailed description of parameters and practical recommendations for selecting them [4]. However, some aspects of the model, such as drying and flooding, and numerical methods for the advective terms are briefly introduced here.

Dynamic changes in flow extent are a critical aspect of many environmental flows, including floods, estuarine flows, coastal flows and dam breaks. Such problems all involve a moving shoreline for transient problems or one whose location is not known a priori in the steady-state case [6]. Both horizontal and vertical moving boundaries typically require additional algorithms to be incorporated into the code to ensure their correct treatment. A number of such algorithms are available, and the method chosen can have significant consequences for both the computational cost and physical realism of the resulting simulations [6]. In general, in a numerical model, the process of drying and flooding is represented by removing grid points from the flow domain that become "dry" when the water level falls and by adding grid points that become "wet" when the water level rises. Several drying/flooding schemes are available in Delft3D-FLOW. The detailed description of these numerical schemes is 
beyond the scope of this paper and can be found in [4]. However, by default, the water depth in each of the grid cell faces (velocity points) of a computational grid cell is determined to decide if the flow should be blocked by a (temporary) thin dam. If the flow at the four faces of a computational grid cell is blocked, this grid cell is set as dry. However, this does not guarantee the water depth at the grid cell centre (water level point) to be positive definite. Therefore, an additional check can be done on the water depth at the centre [4]. Drying and flooding can generate small oscillations in the water levels and velocities. These oscillations are small if the grid sizes are small and the bottom has smooth gradients.

For the spatial discretization of the horizontal advection terms, three options are available in Delft3D-FLOW: the cyclic, Waqua, and flooding schemes. The cyclic and Waqua schemes use higher order dissipative approximations of the advective terms, and the time integration is based on the ADI method, which do not impose a time step restriction [4,7]. The flooding scheme can be applied for problems that include rapidly varying flows such as hydraulic jumps and bores $[4,8]$. The integration of the advection term is explicit, and the time step is restricted by the Courant number for advection. For this scheme, the accuracy in the numerical approximation of the critical discharge rate for flow with steep bed slopes can be increased by the use of a special approximation (slope limiter) of the total water depth at a velocity point downstream. The limiter function is controlled by the user-defined threshold depth for the critical flow limiter [4]. In this study, the flooding scheme with a threshold depth for a critical flow limiter of $0.3 \mathrm{~m}$ was used in consideration of the physics of the flow and bathymetry of the domain. Reducing the threshold depth to $0.15 \mathrm{~m}$ did not affect the results.

As stated by [4], the standard drying and flooding algorithm in Delft3D-FLOW is efficient and accurate for coastal regions, tidal inlets, estuaries and rivers. Also, in combination with the flooding scheme for advection in the momentum equation, the algorithm is also effective and accurate for rapidly varying flows with large water level gradients, such as the flow system, which was modeled in this study.

A smoothing time of $22 \mathrm{~min}$ was selected in the numerical modeling. The smoothing time determines the time interval in which the open boundary conditions are gradually applied, starting at the specified initial condition to the specified open boundary conditions. This smoothing of the boundary conditions prevents the introduction of short wave disturbances into the model.

(7) The uniform background horizontal eddy viscosity $v_{H}^{\text {back }}$ was separately calibrated for low-discharge scenarios LDS and LDC (see Table 1) and high-discharge scenarios HDS and HDC using the described numerical and physical parameters. The procedure for calibrating $v_{H}^{\text {back }}$ is explained for high-discharge scenarios as example. Depths at three locations were considered for calibration, and these depths for the prototype were calculated by upscaling the measured values at the physical model. The locations were upstream the sill at almost midway between the drop and sill (see Figure 8), above the sill and in the middle of the corner wall $D E$. In total, six depth values were considered in this case, and $v_{H}^{\text {back }}$ in the model was manually changed until a reasonable agreement between the upscaled measured depths and calculated depths and an unbiased error distribution were observed. As described earlier, some tolerance was accepted in imposing the upstream water level boundary condition, but no compromise was made for the discharge. It should be emphasized that the flow pattern downstream the sill, around the corner wall $D E$ and C-Ss was the main focus of the study and a small tolerance in depth at far upstream section cannot significantly affect the flow in this zone. A similar procedure was used 
to calibrate $v_{H}^{\text {back }}$ for low-discharge scenarios. The resulting values were $v_{H}^{\text {back }}=0.143$ and $v_{H}^{\text {back }}=0.05 \mathrm{~m} / \mathrm{s}^{2}$ for high and low-discharge scenarios, respectively. Figure 10 shows simulated $v s$. upscaled measured depth values for all three locations under low and high high-discharge scenarios. A mean absolute relative error of about $10 \%$ with a maximum absolute relative error of about $22 \%$ was observed during the calibration procedure. The reasons for this error can be the upscaled measurement error in the physical model and the simple structure of the numerical model for adequately defining the physical process of the flow system. The stage/ruler used to measure the depths in the physical model was accurate to $1 \mathrm{~mm}$. However, a maximum absolute error of $3 \mathrm{~mm}$ can be considered due to the fluctuations in the water surface. Although it is not considered complete turbulence modeling, case studies using a constant eddy viscosity exist in the literature [9]. It was believed that the adopted numerical and physical values can produce results in agreement with the objectives of the study. The main objective of the study was to generate velocity and depth fields in the areas of interest.

Figure 10. Upscaled measured depths vs. simulated values after calibration.

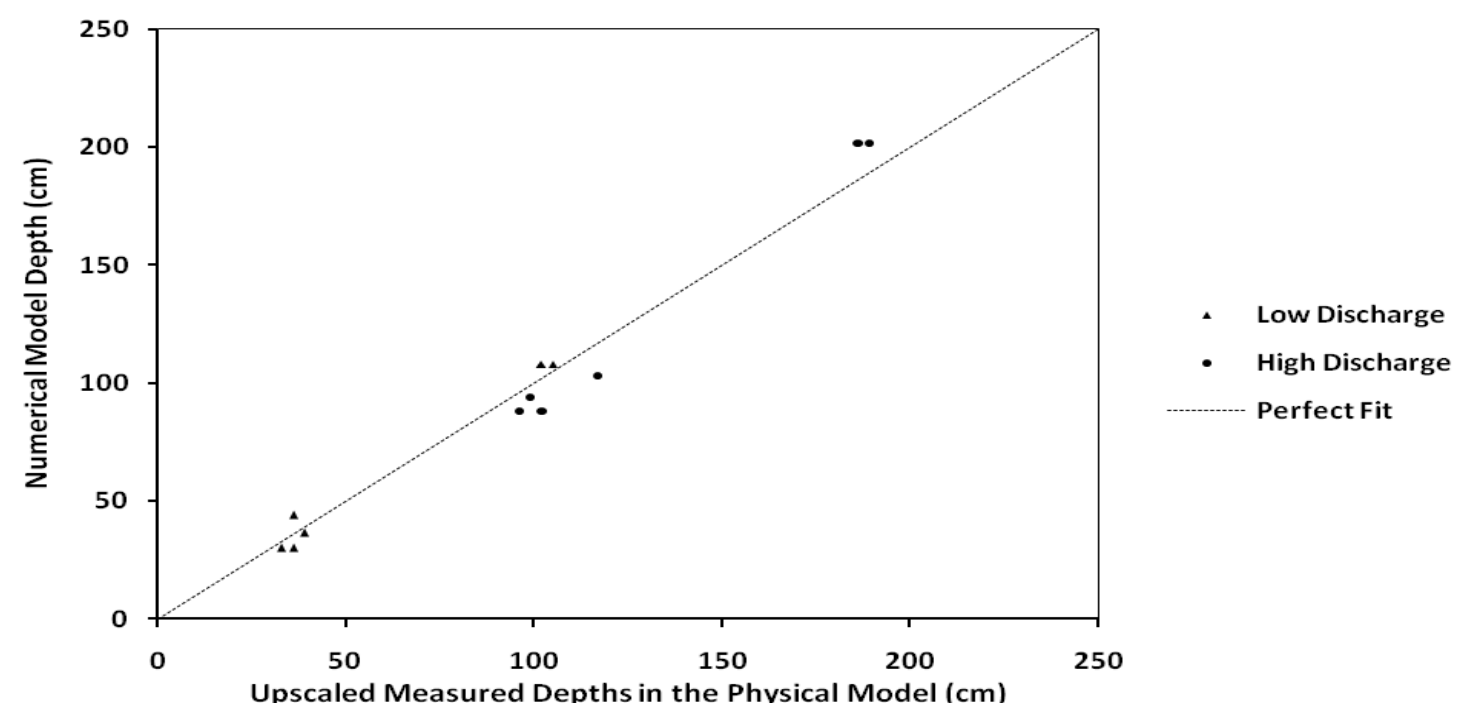

\section{Results and Discussion}

As shown in Figure 8, the flow characteristics in the confined zone after the sill, around the corner wall $D E$ and around the C-Ss are the main results of interest. The effect of having a curved corner at point $\mathrm{D}$ and using guide vanes in the confined zone after the sill are also presented.

For consistency, all of the results are from numerical modeling, which can provide detailed information about the depth, velocity and other parameters of interest such as the Froude number at different locations and discharge splits between the two C-Ss. To gain an insight into the flow characteristics, the HDS scenario (defined in Table 1) is presented first, and the effects of using a corner that is smooth with/without guide vanes under high and low discharges are then discussed.

Figures 11-16 present different flow characteristics for the HDS scenario at the final steady-state condition as extracted from different monitoring and graphing capabilities that are available in Delft3D-FLOW. Each figure gives useful information about different characteristics of the flow system, which can show negative and positive aspects for this design alternative. Figure 11 shows the depth variation in the flow system. The gradual variation in depth towards the drop, sudden change of 
depth at the drop and the backwater effect behind the sill are present in the figure. The presence of a standing wave after the sill along the direction normal to $D E$ is evident in the figure; the wave was also present in the physical model. A smooth corner and vanes were used to reduce the wave height in this zone. Figure 12 presents the distribution of the velocity magnitude in the flow system. Combining the two graphs, results in the distribution of the Froude number in the flow system.

Figure 11. Depth variation in the flow system for HDS scenario (see Table 1).

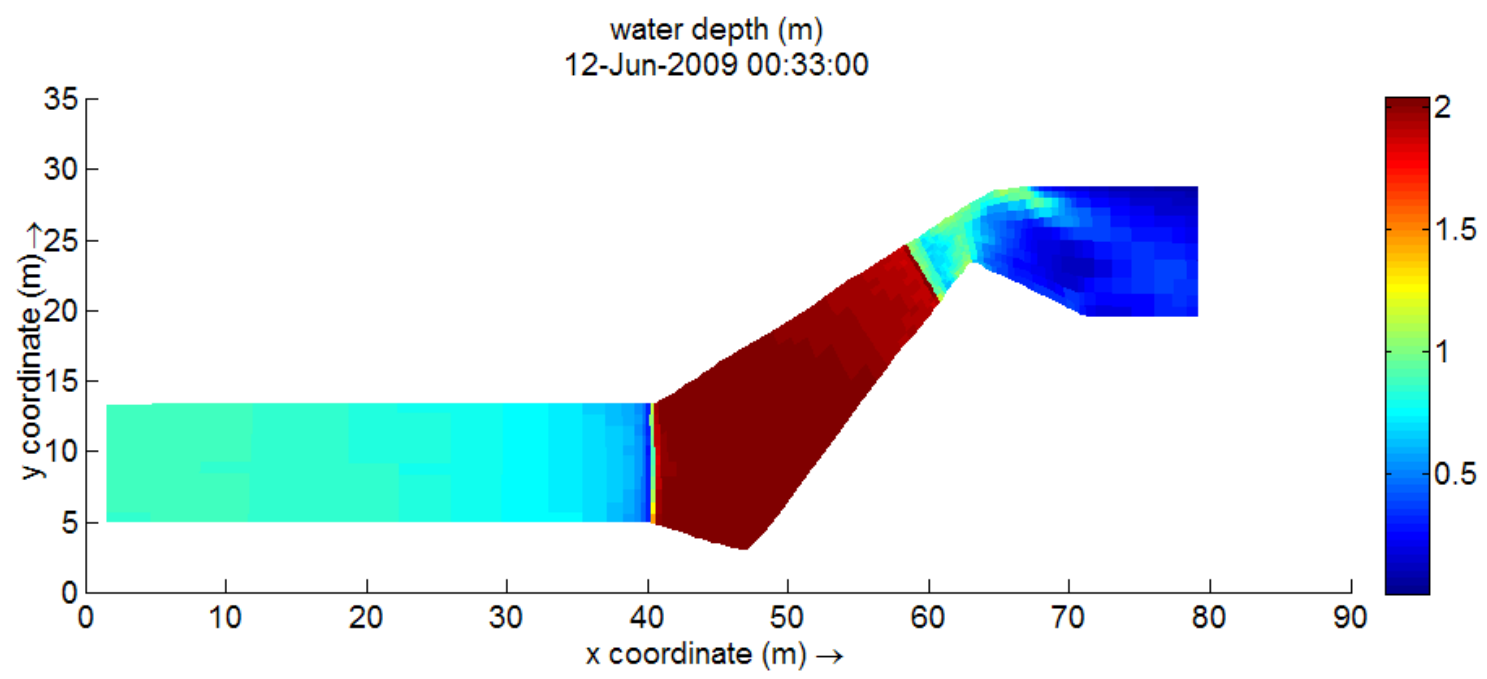

Figure 12. Velocity magnitude variation in the flow system for HDS scenario.

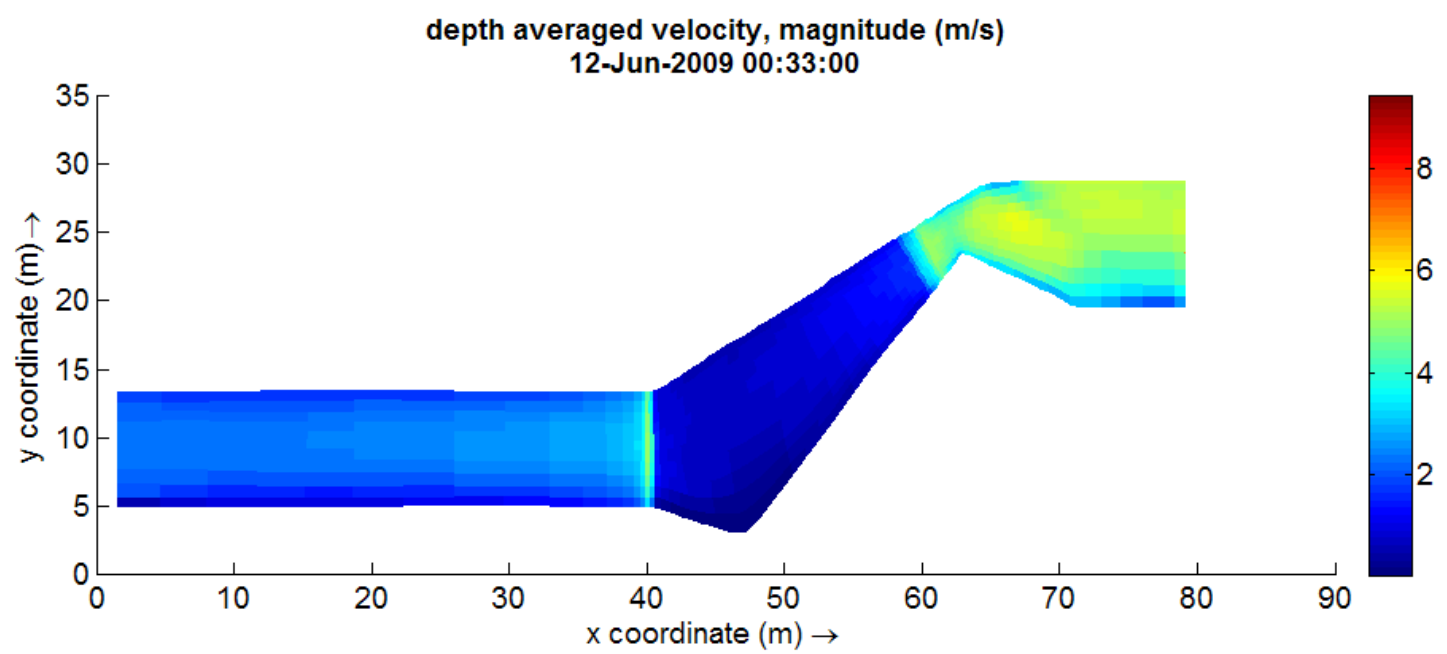

Figures 13 and 14 show the velocity vectors in the flow domain. The figures show that the velocity vectors are more uniform and normal to the $\mathrm{C}-\mathrm{S}$ along $F G$, while they form an angle of about $30^{\circ}$ with the C-S along screen EF.

Figures 15 and 16 show how the discharge along the C-Ss, which is influenced by initial and boundary conditions, approaches the final steady-state condition. They also show the division of the total discharge between the two C-Ss. Such information can indicate the percentage of the discharge received by each screen. 
Figure 13. Velocity vector variation in the flow system for HDS scenario.

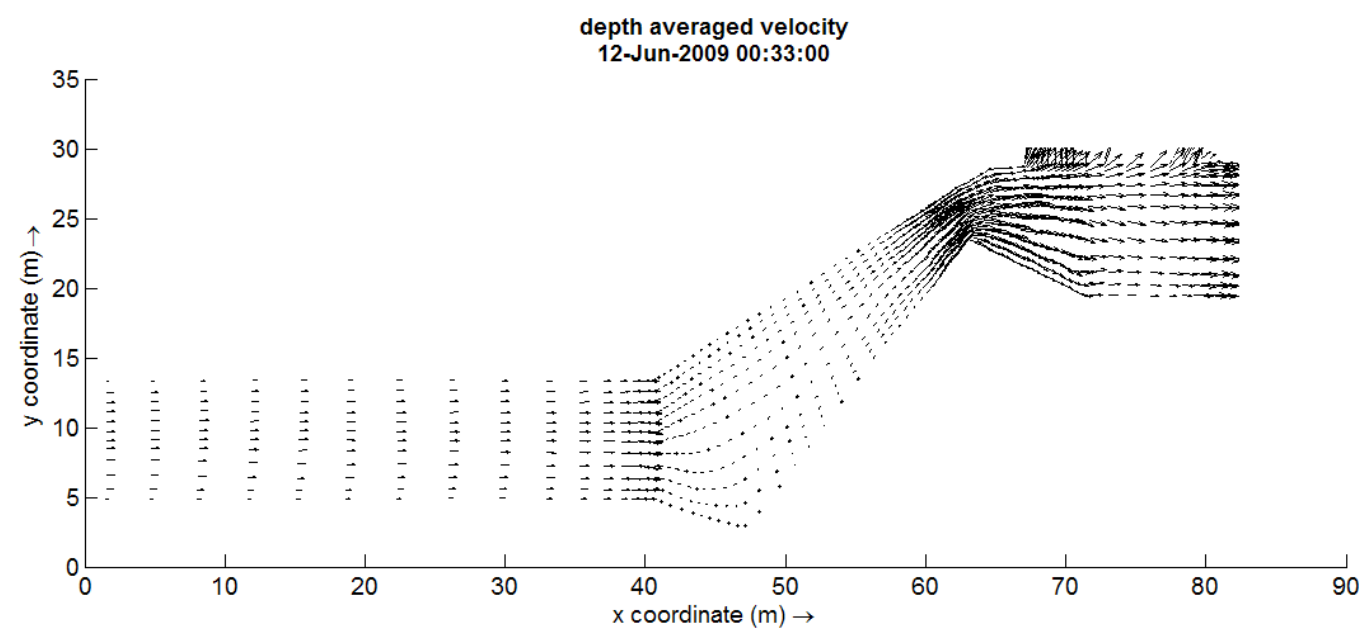

Figure 14. Velocity vector variation in the flow system for HDS scenario zoomed around the C-Ss.

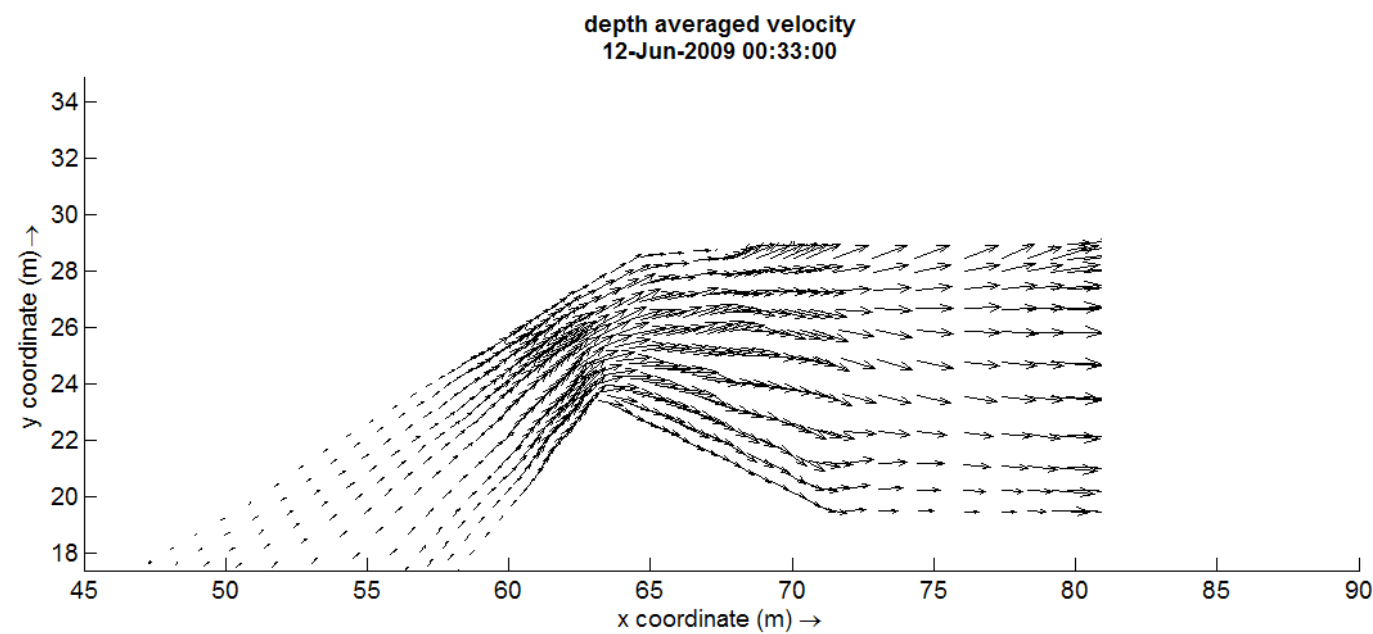

Figure 15. Instantaneous discharge $v s$. time across C-S EF for HDS scenario.

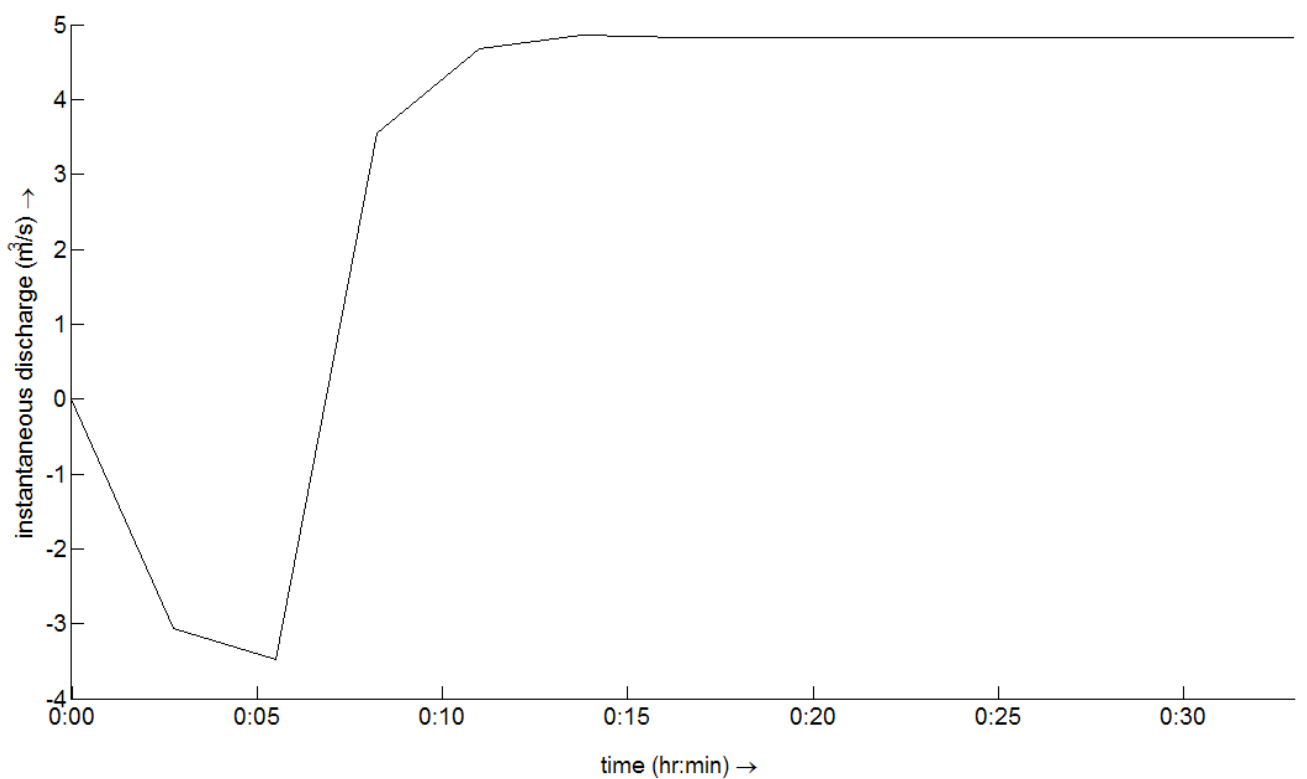


Figure 16. Instantaneous discharge $v s$. time across C-S FG for HDS scenario.

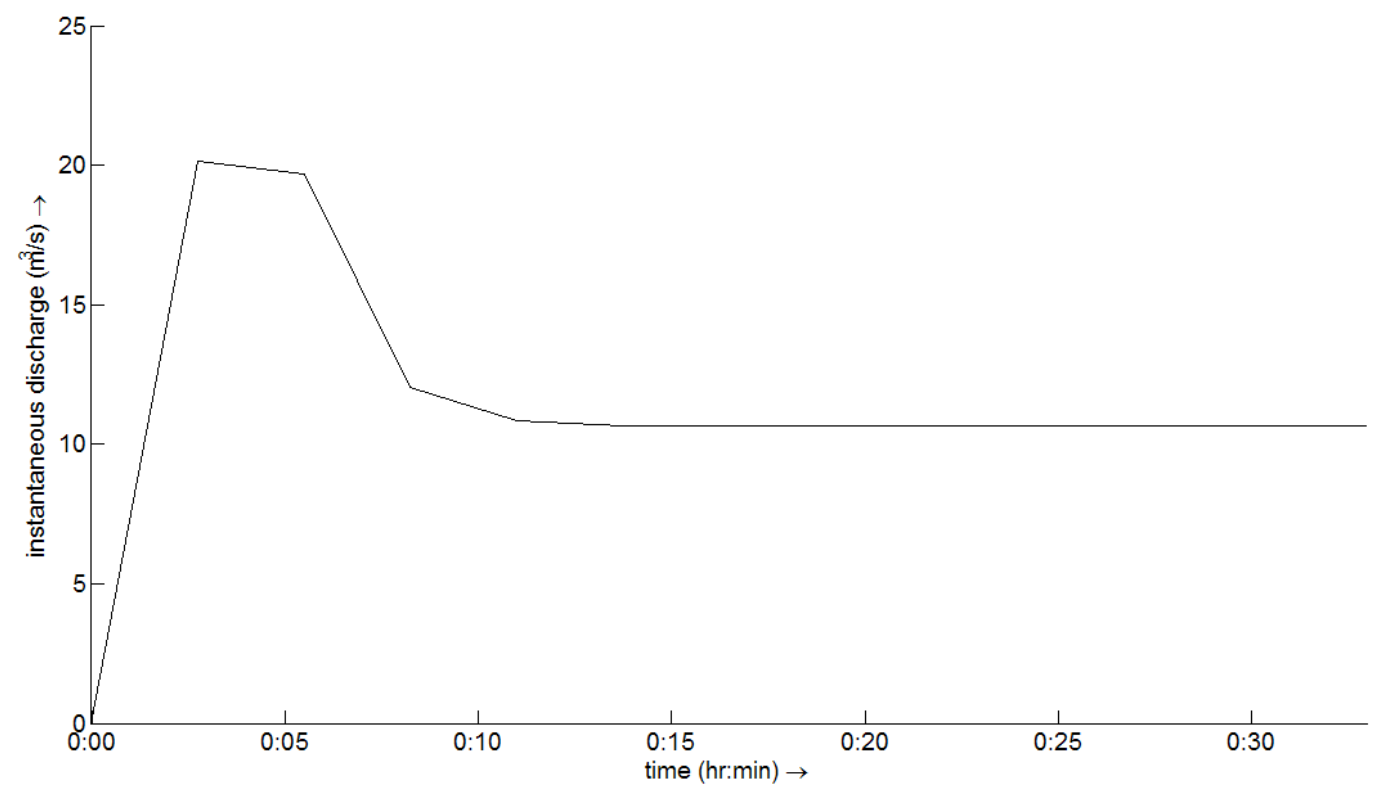

Figures 17-19 concentrate on the water depth, flow velocity and Froude number (defined as the velocity divided by the square root of depth times gravitational acceleration, or $F r=V / \sqrt{g y}$ ) along the C-Ss. As Figures 17 and 18 show, although the velocity is reasonably uniform along the C-S $E F$, the depth is very shallow for nearly one-third of the C-S length at the end. In other words, the C-S does not act effectively in this zone even under high design discharges. The Froude numbers are also very high in this zone due to the shallow depths.

Other possible minor changes in the design are the use of a curved small wall with/without an unsubmerged guide vane to reduce the height of the standing wave across the section perpendicular to wall $D E$. Figure 20 shows the water depth distribution for such a design, with the guide vane located in the middle of the flow with a length of about $2.9 \mathrm{~m}$ (HDCV scenario). As the figure shows, although the overall standing wave height is reduced, there is flow separation along the vane.

Figure 17. Water depth variation along C-Ss for HDS scenario (at monitoring points).

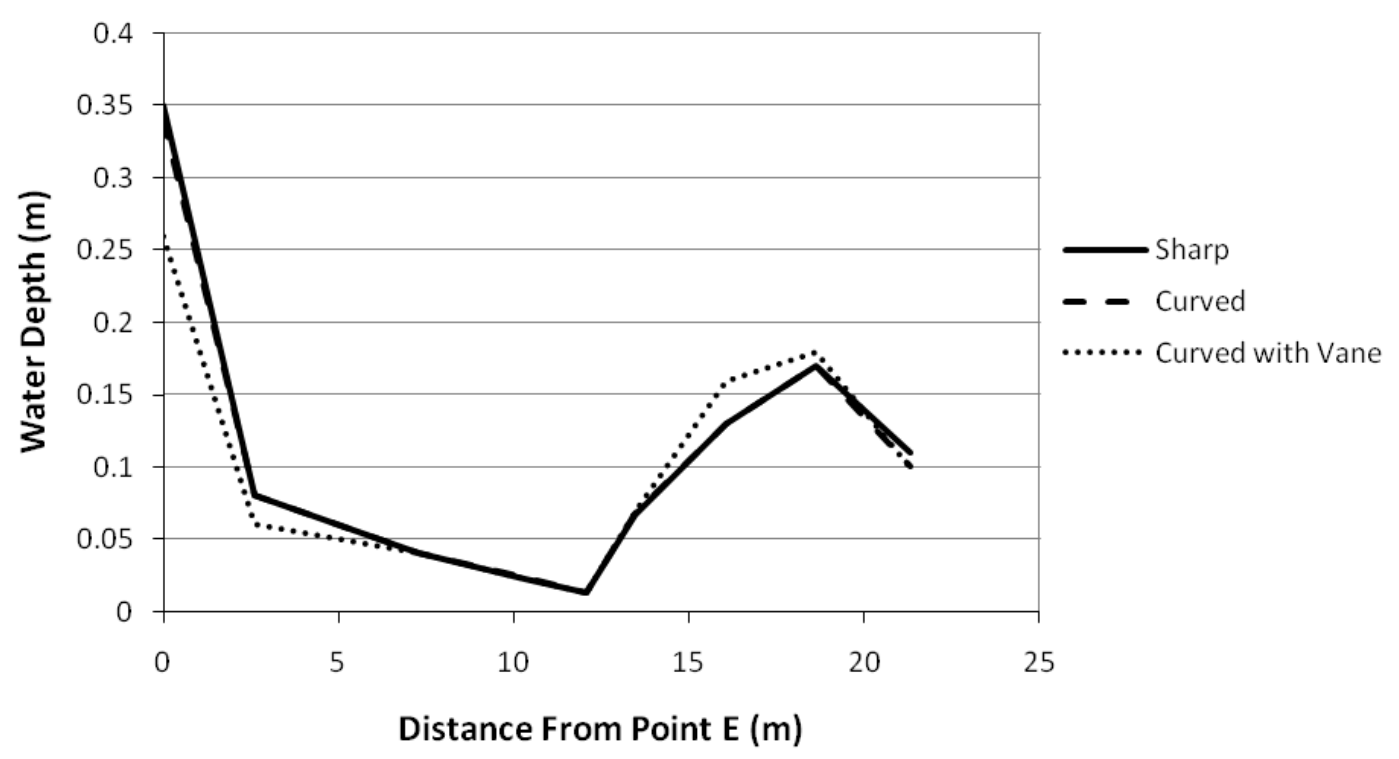


Figure 18. Flow velocity variation along C-Ss for HDS scenario (at monitoring points).

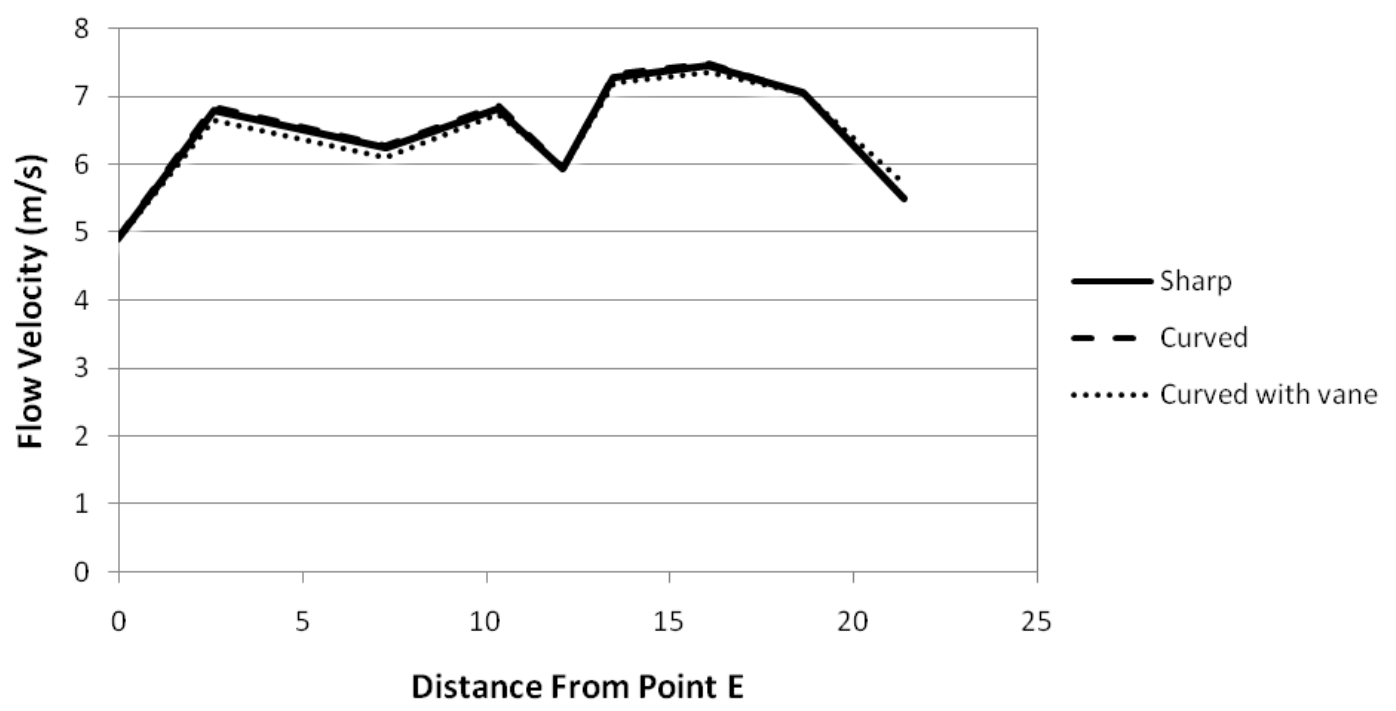

Figure 19. Froude number variation along C-Ss for HDS scenario (at monitoring points).

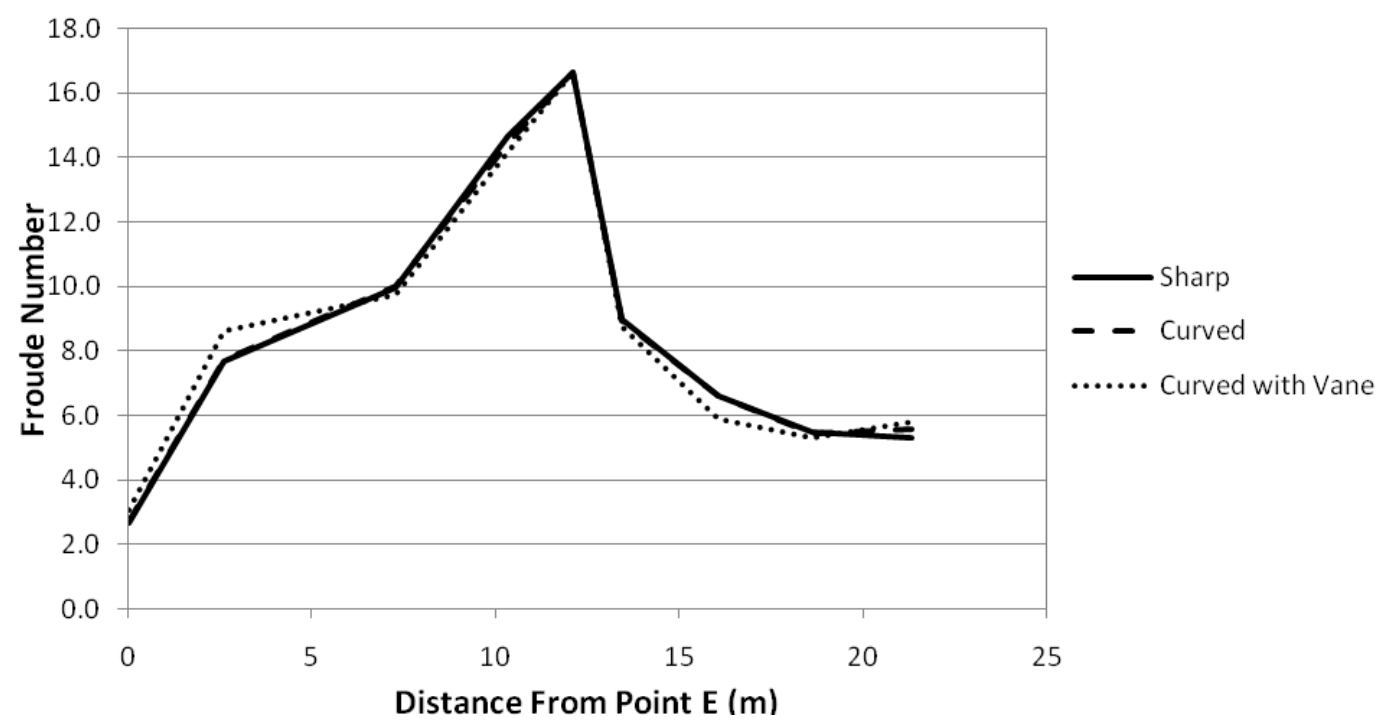

Figure 20. Depth variation in the flow system for HDCV scenario (see Table 1).

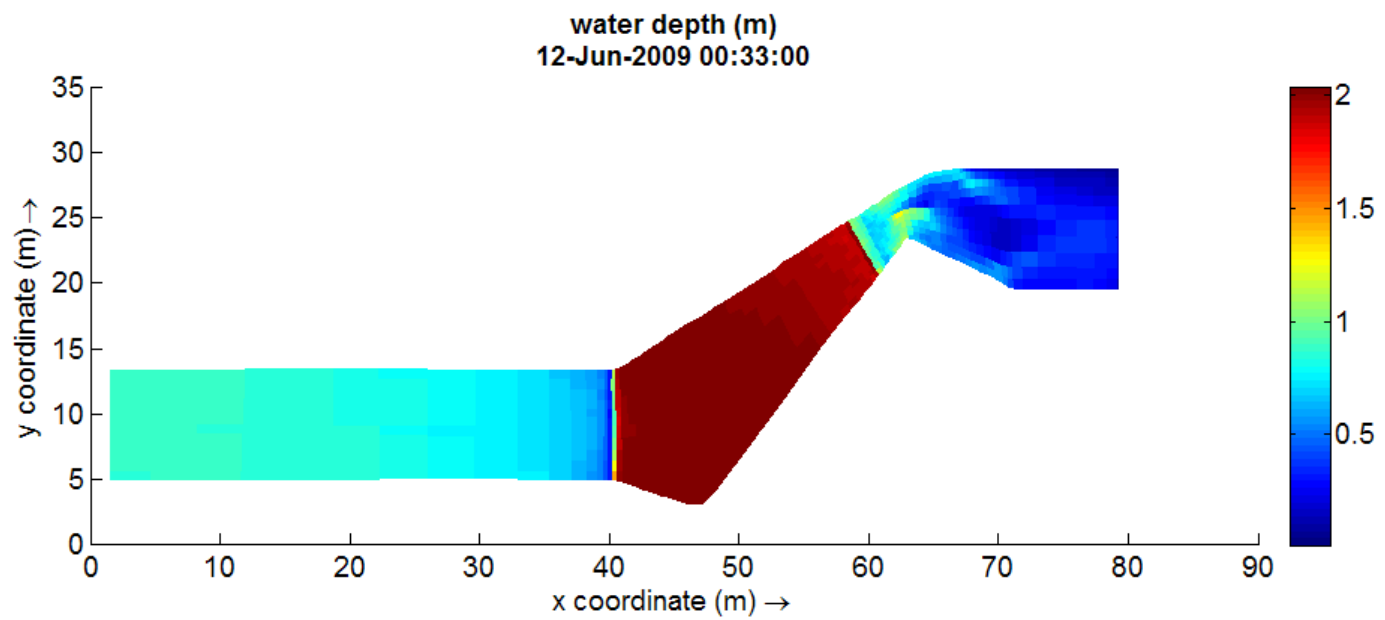


Table 2 presents a summary of all design parameters and variables involved in the problem for all scenarios defined in Table 1. Valuable results can be drawn from the data reported in the table and observations made in the numerical model outputs. The physical model observations were also in agreement with the numerical model outputs, which helped validate the numerical results. As an example, Figure 21 shows the flow pattern around the C-S EF. Such cost-effective observations supported the numerical results and outputs. The main results are as follows.

Table 2. Design variables/parameters for different flow scenarios.

\begin{tabular}{|l|c|c|c|c|c|c|}
\hline \multirow{2}{*}{ Design variable } & \multicolumn{3}{|c|}{ High discharge scenarios } & \multicolumn{3}{c|}{ Low discharge scenarios } \\
\cline { 2 - 7 } & HDS & HDC & HDCV & LDS & LDC & LDCV \\
\hline Discharge $\left(\mathrm{m}^{3} / \mathrm{s}\right)$ & 15.49 & 15.49 & 15.49 & 3.38 & 3.38 & 3.38 \\
\hline Discharge along C-S $E F\left(\mathrm{~m}^{3} / \mathrm{s}\right)$ & 4.86 & 4.90 & 4.05 & 1.11 & 1.16 & 0.96 \\
& $(31.4 \%)$ & $(31.6 \%)$ & $(26.1 \%)$ & $(32.8 \%)$ & $(34.3 \%)$ & $(28.4 \%)$ \\
\hline Discharge along C-S $F G\left(\mathrm{~m}^{3} / \mathrm{s}\right)$ & 10.63 & 10.58 & 10.43 & 2.27 & 2.22 & 2.42 \\
& $(68.6 \%)$ & $(68.4 \%)$ & $(73.9 \%)$ & $(67.2 \%)$ & $(65.7 \%)$ & $(71.6 \%)$ \\
\hline Range of velocity magnitude along C-S $E F(\mathrm{~m} / \mathrm{s})$ & 4.93 & 4.95 & 4.89 & 0.32 & 1.30 & 0.15 \\
& 5.95 & 5.95 & 5.94 & 4.68 & 4.72 & 4.73 \\
\hline Range of velocity magnitude along C-S FG $(\mathrm{m} / \mathrm{s})$ & 5.50 & 5.51 & 5.72 & 4.43 & 4.4 & 4.58 \\
& 7.29 & 7.32 & 7.21 & 5.33 & 5.32 & 5.25 \\
\hline Range of depth along C-S $E F(\mathrm{~m})$ & 0.013 & 0.013 & 0.013 & 0.014 & 0.018 & 0.015 \\
& 0.350 & 0.340 & 0.260 & 0.108 & 0.108 & 0.088 \\
\hline Range of depth along C-S FG $(\mathrm{m})$ & 0.067 & 0.068 & 0.069 & 0.021 & 0.022 & 0.021 \\
& 0.170 & 0.170 & 0.180 & 0.040 & 0.041 & 0.042 \\
\hline Range of Froude number along C-S $E F$ & 2.7 & 2.7 & 3.1 & 0.9 & 3.1 & 0.4 \\
& 16.7 & 16.7 & 16.6 & 12.7 & 12.1 & 14.2 \\
\hline Range of Froude number along C-S FG & 5.3 & 5.6 & 5.8 & 8.1 & 8.3 & 7.9 \\
& 9.0 & 9.0 & 8.8 & 11.1 & 11.0 & 11.1 \\
\hline Maximum depth along wall $D E(\mathrm{~m})$ & 1.08 & 0.98 & 0.74 & 0.44 & 0.365 & 0.304 \\
\hline
\end{tabular}

Figure 21. Flow pattern around C-S $E F$, wall $D E$ and point $E$.

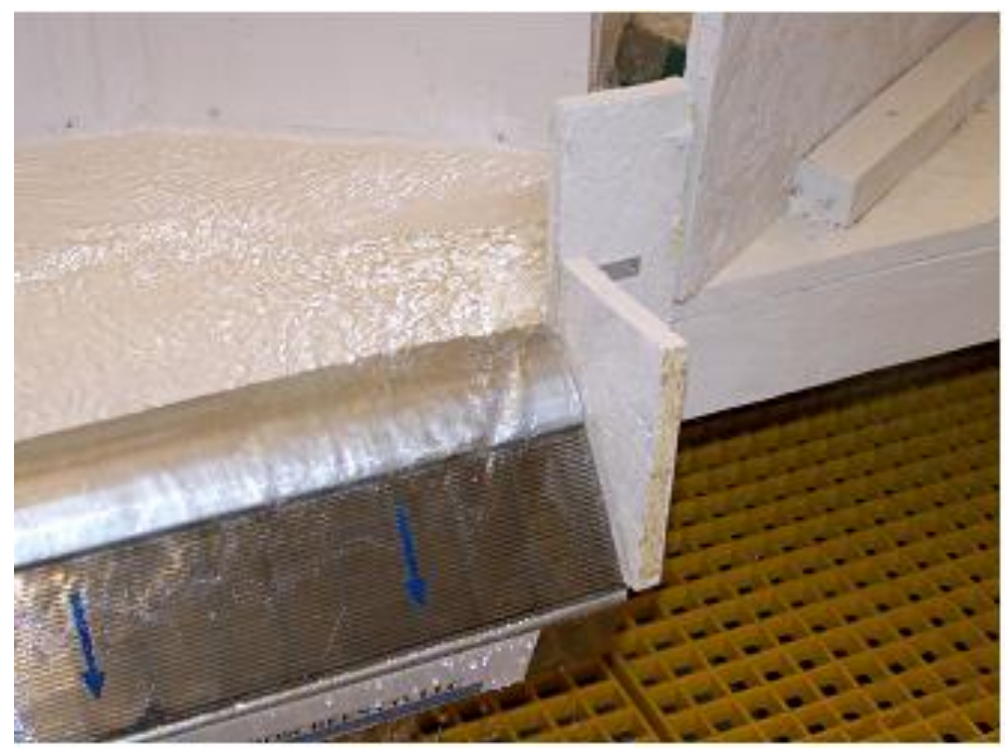


(1) Flow after the sill is highly supercritical. A standing wave exists in the confined zone after the sill. A Froude number of up to about 17 is observed in the zone behind and around the C-Ss. Meanwhile, it was found that the calculated local cavitation index was higher than the incipient (critical) cavitation index considered for this structure. This indicates that cavitation does not occur in the hydraulic system.

(2) Although the percentage of discharge absorbed by C-S EF is a little higher for low discharges, when a smoothed curved corner wall is used at $E$, an average of about $30 \%$ of the total discharge flows towards $E F$. The per unit length discharge values are about 0.39 and $0.08 \mathrm{~m} / \mathrm{m} \cdot \mathrm{s}$ for high and low discharges, respectively. The corresponding values for the C-S $F G$ are about 1.05 and $0.23 \mathrm{~m}^{3} / \mathrm{m} \cdot \mathrm{s}$, which are much higher compared to the $E F$ values.

(3) Flow is relatively uniformly distributed along C-S $F G$, and velocity vectors are normal to the C-S. However, flow around C-S EF is more variable in terms of depth and velocity, and velocity vectors form an angle of about $30^{\circ}$ with the $E F$ direction. In this case, use of a C-S normal to the velocity vectors to form an angle of about $150^{\circ}$ at point $F$ with the $F G$ direction is recommended. Apart from the improvement in hydraulic performance, such a design reduces the effective length of the C-S EF, which also decreases cost. The discharges per unit length of C-S EF will be about 0.78 and $0.16 \mathrm{~m}^{3} / \mathrm{m} \cdot \mathrm{s}$ for high and low discharges, respectively; they are comparable to the corresponding values for C-S FG.

(4) Using a curved corner wall at point $D$ reduces the maximum depth along DE under high discharges for with/without vane scenarios by about $32 \%$ and $9 \%$, respectively. These numbers are about $30 \%$ and $16 \%$ for low discharges. In general, using a curved corner wall at this location is recommended since it does not affect the flow pattern, construction or operation.

(5) Observation in the physical model and examination of the numerical model outputs indicate that using a smoothly curved $\mathrm{C}-\mathrm{S}$ at the corner point $F$ improves the flow pattern and system performance for removing debris.

\section{Conclusions}

A simple numerical model was established using the Delft3D-FLOW CFD model to analyze flow in a complicated design alternative for a diversion structure with Coanda-effect screens. An inexpensive physical model was also used to estimate some physical parameters related to the numerical model and observe flow patterns in different parts of the flow system. Using numerical tools and physical modeling in conjunction for analysis of flow behind and around the Coanda-effect screens provided screen designers and manufacturers with some design parameters/variables and flow detailing for the effective design and setup of the screens.

\section{Acknowledgments}

The authors thank Albuquerque Metropolitan Arroyo Flood Control Authority (AMAFCA) for their financial and technical support in setting up the physical model of this study and WL|Delft Hydraulics (now Deltares) for giving the authors full access to Delft3D-FLOW and providing technical support. The first author wishes to acknowledge Ferdowsi University of Mashhad for its support during his sabbatical leave. 


\section{References}

1. Wahl, T.L. Hydraulic performance of Coanda-effect screens. J. Hydraul. Eng. 2001, 127, 480-488.

2. Wahl, T.L. Design Guidance for Coanda-effect Screens; Water Resources Research Laboratory Research Report R-03-03; USBR (United States Bureau of Reclamation): Denver, CO, USA, 2003.

3. Pender, G.; Morvan, H.P.; Wright, N.G.; Ervine, D.A. CFD for environmental design and management. In Computational Fluid Dynamics: Applications in Environmental Hydraulics; Bates, P.D., Lane, S.N., Ferguson, R.I., Eds.; John Wiley \& Sons Ltd.: Oxford, UK, 2005; pp. 487-510.

4. WL|Delft Hydraulics. Delft3D-FLOW User Manual; Version 3.14, revision 5661; Delatres: Delft, The Netherlands, 2008; p. 630.

5. Rodi, W. Turbulence Models and Their Applications in Hydraulics: A State-of-the-Art Review; IAHR Monograph Series; A.A. Balkema: Rotterdam, The Netherlands, 1980; p. 124.

6. Bates, P.D.; Horritt, M.S. Modelling wetting and drying processes in hydraulic models. In Computational Fluid Dynamics: Applications in Environmental Hydraulics; Bates, P.D., Lane, S.N., Ferguson, R.I., Eds.; John Wiley \& Sons Ltd.: West Sussex, UK, 2005; pp. 121-146.

7. Stelling, G.S.; Leendertse, J.J. Approximation of Convective Processes by Cyclic AOI Methods. In Proceedings of the 2nd International Conference on Estuarine and Coastal Modeling, Tampa, FL, USA, 13-15 November 1992; Spaulding, M.L., Bedford, K., Blumberg, A., Cheng, R., Swanson, C., Eds.; American Society of Civil Engineers: Reston, VA, USA, 1991; pp. 771-782.

8. Stelling, G.S.; Duinmeijer, S.P.A. A staggered conservative scheme for every Froude number in rapidly varied shallow water flows. Int. J. Numer. Methods Fluids 2003, 43, 1329-1354.

9. Sturm, T.W. Open Channel Hydraulics, 2nd ed.; McGraw-Hill Companies: Bethesda, MD, USA, 2010.

(C) 2011 by the authors; licensee MDPI, Basel, Switzerland. This article is an open access article distributed under the terms and conditions of the Creative Commons Attribution license (http://creativecommons.org/licenses/by/3.0/). 